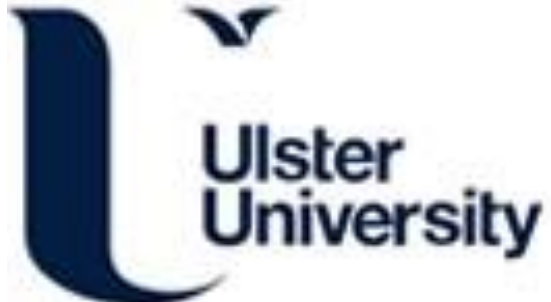

\section{Acetylene-argon plasmas measured at an rf-biased substrate electrode for diamond- like carbon deposition: II. lon energy distributions}

Baby, A., Mahony, CMO., Lemoine, P., \& Maguire, PD. (2011). Acetylene-argon plasmas measured at an rfbiased substrate electrode for diamond-like carbon deposition: II. Ion energy distributions. Plasma Sources Science and Technology, 20(015004). https://doi.org/10.1088/0963-0252/20/1/015004

Link to publication record in Ulster University Research Portal

\section{Published in:}

Plasma Sources Science and Technology

Publication Status:

Published (in print/issue): 07/01/2011

DOI:

10.1088/0963-0252/20/1/015004

\section{Document Version}

Publisher's PDF, also known as Version of record

\section{General rights}

Copyright for the publications made accessible via Ulster University's Research Portal is retained by the author(s) and / or other copyright owners and it is a condition of accessing these publications that users recognise and abide by the legal requirements associated with these rights.

\section{Take down policy}

The Research Portal is Ulster University's institutional repository that provides access to Ulster's research outputs. Every effort has been made to ensure that content in the Research Portal does not infringe any person's rights, or applicable UK laws. If you discover content in the Research Portal that you believe breaches copyright or violates any law, please contact pure-support@ulster.ac.uk. 
Acetylene-argon plasmas measured at an rf-biased substrate electrode for diamond-like carbon deposition: II. Ion energy distributions

This article has been downloaded from IOPscience. Please scroll down to see the full text article.

2011 Plasma Sources Sci. Technol. 20015004

(http://iopscience.iop.org/0963-0252/20/1/015004)

View the table of contents for this issue, or go to the journal homepage for more

Download details:

IP Address: 194.80.87.141

The article was downloaded on 25/03/2011 at 14:02

Please note that terms and conditions apply. 


\title{
Acetylene-argon plasmas measured at an rf-biased substrate electrode for diamond-like carbon deposition: II. Ion energy distributions*
}

\author{
A Baby, C M O Mahony, P Lemoine and P D Maguire \\ Nanotechnology and Integrated Bio-Engineering Centre (NIBEC), University of Ulster, Newtownabbey, \\ BT37 0QB, UK \\ E-mail: pd.maguire@ulster.ac.uk
}

Received 12 November 2008, in final form 2 August 2010

Published 7 January 2011

Online at stacks.iop.org/PSST/20/015004

\begin{abstract}
Ion energy distributions (IEDs) have been determined at the radio frequency (rf)-biased electrode in an inductively coupled acetylene-argon plasma for various substrate bias voltages and frequencies under conditions suitable for diamond-like carbon (DLC) and polymer-like film deposition. These are compared with those obtained at a capacitively coupled plasma grounded wall. In the former, for pressures $<25 \mathrm{mTorr}$, the IEDs exhibit bimodal structures with peak separation values that follow the expected voltage and frequency dependences. At higher pressures, $120 \mathrm{~m}$ Torr, the bimodal structure is replaced by a single peak. For all conditions the dominant ion is $\mathrm{Ar}^{+}$or $\mathrm{ArH}^{+}$despite the set flow ratio of $\mathrm{C}_{2} \mathrm{H}_{2}$ : Ar of $2: 1$ and this can be attributed to the high electron dissociation of the parent molecule. DLC films indicate a peak hardness at an ion energy of around $90 \mathrm{eV}$ and a very sharp fall in hardness is noted beyond this value. This is similar to the observed $\mathrm{sp}^{3}$-bond formation in hydrogen-free tetrahedral amorphous carbon or bias-sputtered films. However, due to the lack of carbon-based ions, an alternative mechanism is likely based on argon knock-on implantation of surface adsorbed carbon species. The results have shown that the use of high-frequency bias or bias harmonics may lead to much narrower IEDs.
\end{abstract}

(Some figures in this article are in colour only in the electronic version)

\section{Introduction}

Diamond-like or amorphous carbons (DLC) represent a class of technologically important thin film materials. The ability to vary properties, such as hardness, Young's modulus, surface roughness, electrical resistance, thermal conductivity, density, refractive index, among others, offers considerable versatility in mechanical, electrical, optical and more recently biomedical applications. Intensive study over the past decade, using a wide range of complementary high resolution analysis techniques and atomistic modelling, has resulted in detailed understanding of the relationship between functional properties and material structure. Nevertheless, this work has been most successful in

* This paper was presented as an invited talk at the 19th European Sectional Conference on Atomic and Molecular Physics of Ionized Gases, Granada, Spain, 15-19 July 2008. See stacks.iop.org/PSST/18/3. the case of hydrogen-free tetrahedrally bonded or tetrahedral amorphous carbon (ta-C). Filtered ion beams (mass-selected or filtered cathodic arc) are generally used for ta-C deposition and thus the relationship between deposition conditions and material properties can be readily established. In particular it is accepted that within an ion energy (IE) window of approximately $50-100 \mathrm{eV}$, energetic species subplantation and $\mathrm{sp}^{3}$ carbon-bond formation are favoured over high-energy relaxation to graphitic $\mathrm{sp}^{2}$-bonding resulting in diamond-like ultra-hard and smooth thin films. Unfortunately issues such as cost, plant complexity, high intrinsic stress and line of sight planar deposition restrict the use of ta-C to high end specialist applications.

Hydrogenated amorphous carbon $(\mathrm{a}-\mathrm{C}: \mathrm{H})$, although it does not approach the quality of ta-C, is suitable for many applications and can be routinely deposited in simple 
capacitively coupled radio frequency (rf) plasma enhanced chemical vapour deposition (PECVD) systems. Hence it is widely favoured. Research has investigated factors such as power, bias, pressure, hydrocarbon precursors and inert gas dilution in order to optimize processes for a given application. More detailed plasma studies are seriously hampered by instrument and probe contamination and the species-rich plasma environment limits our ability to derive accurate relationships between structure, function and deposition conditions. From the limited number of mass spectrometry and IE studies, we understand in general that energetic hydrocarbon ions bombarding a surface play a major role in a-C: $\mathrm{H}$ formation. These act in concert with radical adsorption; the particular growth pathway being dependent upon the dominant radical which in turn depends upon choice of precursor gas (e.g. $\mathrm{CH}_{4}, \mathrm{C}_{2} \mathrm{H}_{2}$, etc), pressure and its dilution (e.g. Ar). Jacob [1] and co-workers [2] have highlighted, through extensive beam experiments coupled with complicated in situ materials diagnostics, the highly complex species interactions at play, both synergistic and 'anti-synergistic'. The interplay between ion bombardment (inert and reactive), radical adsorption and desorption as well as hydrogen reactions via molecular dissociation, adsorption/desorption, bond formation and etching is modelled in detail but transferring these model outcomes to applications processing in standard systems is still problematic. Overall, from a practical applications perspective, the ability to predict and tailor a-C : H properties is limited. In fact, it is accepted that in standard PECVD, the a-C:H properties are relatively insensitive to plasma input variables. At very low powers or grounded electrodes, the low self-bias results in soft polymeric a-C:H with a large bandgap, while at very high powers (bias $>500 \mathrm{~V}$ ), the graphitic phase dominates. A number of other, more specialist, plasma sources have been reported including inductively coupled plasma (ICP), ECR [1] and cascaded arc [3] and found to be viable. In particular, these systems offer higher deposition rates due to higher plasma densities achievable at low to moderate substrate biases. Future directions in a-C : H processing include accommodating complex and threedimensional substrates for biomedical and other applications, large area coatings (e.g. packaging, barrier and anti-corrosion layers) and a wider range of substrate materials (e.g. polymers, non-carbide forming metals).

\subsection{Ion energy distributions}

Ion energy distributions (IEDs) in rf plasmas have long been of interest, particularly for the development of high specification etch processes in semiconductors and over the past four decades, numerous experimental and simulation studies have been carried out. Early models, e.g. [29, 30], established the basic IED dependence on rf frequency, sheath width and ion mass. Studies, e.g., by Coburn and Kay [20], Kohler et al [31], Kuypers and Hopman [32], among others, provided experimental support for such models under a range of conditions. In a collisionless plasma, the IED shape is determined by the ratio of ion transit time across the sheath to the $\mathrm{rf}$ period $(\tau / T)$, hence the dependence on ion mass, rf frequency and sheath width. At low frequencies, the ion transit time is much less than the rf period and hence the energy gained by an individual ion strongly depends on the phase at which it entered the sheath. For a sinusoidal rf voltage, the number of ions entering the sheath per unit time is greatest at the minimum and maximum rf voltages. This leads to the standard broad and bimodal IED with a width, $\Delta E$, between the two peaks that approaches the difference in sheath potential excursions. At high rf frequencies, the ion transit time is much longer than the rf period and the ions respond only to the average field. Analytical calculations [30] for this case show a direct relationship between IED width, $\Delta E$, and the product of rf amplitude $\left(V_{\text {rf }}\right)$ and ion transit ratio $(\tau / T)$. As the ratio increases the IED width decreases until the two peaks merge resulting in a narrow monoenergetic IED. However, in many applications, the plasma operates in a more complex transition regime between these high and low frequency conditions. This depends on many factors such as the characteristics of the plasma system, plasma density, pressure and gas mixture and has been the focus of intensive study.

Sobelewski et al [18] observed the dependence of IED shape on sheath voltages for various frequency ranges, particularly at low frequencies. At mid-frequencies, some energy averaging occurs causing the low-energy peak $\left(E_{\min }\right)$ to shift up in energy and the high-energy peak $\left(E_{\max }\right)$ to shift down resulting in a narrower IED, these shifts being greater for heavier ions. As the frequency increases, greater averaging occurs until the single-peak high-frequency case is reached. The ratio of high- to low-energy peak heights also increases with frequency, in this range, especially for the heavier ions. In a review, Kawamura et al [33] considers the capacitively coupled plasma (CCP) system and highlights how the ratio of IED peak heights depend on the shape of the sheath potential waveform, which is non-sinusoidal due to the effect of non-linear sheath impedance. The dominant peak (low or high energy) depends on whether the sheath is resistive or capacitive, respectively, as this affects the shape of the potential waveform. Typically, the low-energy peak is greater at low frequency and as frequency increases, peak heights tend to equalize. However, for asymmetric area electrodes, common in most CCP systems, at intermediate frequencies, the peak height asymmetry persists even with a capacitive sheath. Miller and Riley [34] developed a semi-analytical model of the rf sheath that determines the plasma sheath response to an imposed rf-biased voltage, allowing the time varying sheath width to be included within an electrical model of the plasma. They observed strong sensitivity of the IED to external rf circuit parameters and noted the IED is not necessarily a unique function of these parameters.

Plasma IED measurements were undertaken initially in standard capacitively coupled systems and later in high density ICP systems, e.g. [35-37]. In the latter, under ideal conditions, the plasma potential has a dc but no rf component and hence the IED for the sheath at a grounded wall is a single peak. Kortshagen and Zethoff [35] contrasted the difference between a pure inductive case resulting in a low-energy single peak and a similar ICP discharge with a large capacitive component (no Faraday shield) where sheaths are larger and the energy 
spectrum is broad, with a high average energy. In an ICP with an rf-biased capacitively driven lower electrode, the timevarying voltage difference between plasma and electrode can lead to a bimodal IED. In these discharges, the plasma density is normally high $\left(\sim 10^{11} \mathrm{~cm}^{-3}\right)$, the sheaths thin and at typical operating frequencies $(13.56 \mathrm{MHz}), \tau / T$ is less than 1 . Other high density systems studied in detail include ECR plasmas $[1,38-40]$ which are shown to be essentially a source of almost monoenergetic low-energy ions.

Techniques for measurement of IEDs have included electrostatic deflection, e.g. [19, 20, 31, 32], cylindrical mirror analysers, e.g. [41], and retarding field analysers (RFAs), e.g. $[23,37]$. A particular challenge is to perform the measurement at the driven electrode where the whole analyser is set to follow the rf signal [41] and requires, for example, optocoupling for signal extraction [19,32]. Wild and Koidl [23] used an 'inverted' CCP configuration whereby the smaller electrode (normally driven) was grounded and the 'wall' driven. Edelberg et al [42,43] were able to measure IEDs at the rf-biased electrode in $\mathrm{Ar}, \mathrm{Ne}, \mathrm{Ar}-\mathrm{Ne}, \mathrm{O}_{2}$ and $\mathrm{O}_{2}-\mathrm{CF}_{4}$ discharges over a wide range of plasma operating parameters, including ICP power, bias power and mass, using a compact opto-isolated RFA. Bimodal distributions resulting from IE modulation in the sheath were observed; in gas mixtures multiple IED peaks were ascribed to ions of different masses. Recently Gahan et al [44] demonstrated a compact electronically isolated RFA with a device thickness similar to $\mathrm{Si}$ wafer and hence avoiding the need for differential pumping. However, for more complex chemistries, ion species identification is required.

\subsection{Mass-selected IED}

There are a number of studies where mass spectrometry is incorporated with IE analysis to provide mass and energy analysis (MEA) [18,45-47]. However, integrating the required hardware into a powered electrode is difficult since the entire instrument must be rf biased. To overcome this, Sobolewski et al [18] used an inverted configuration where the MEA orifice, on a sidewall, is grounded. When the lower electrode is rf biased, the developed rf voltage is shared across the electrode and wall sheaths, allowing the study of rf effects with mass and frequency. However, the wall sheath impedance limited the bias amplitudes and frequency range. Mizutani et al $[48,49]$ were able to install a MEA system within a powered electrode and compared dc and rf-biased conditions on mass-selected IEDs, at a single frequency. Hallil et al [50] used a commercial MEA system within a powered electrode but isolated from it. A similar configuration was analysed in detail by Woodworth et al $[36,51]$ and compared with IEDs from RFA measurements at the same location. Isolation of the MEA from the rf-biased electrode results in rf-modulated fields between the MEA orifice and the first MEA ion lens. This can impose additional rf modulation onto ions which have come through the orifice, especially if the ion transit time between orifice and lens is less than the rf period. The impact of ion dynamics and ion transmission optics in such MEA systems was investigated by O'Connell et al [47] along with two-dimensional PIC simulations of the sheath.
Identification of ion species is critical for understanding complex gas mixtures where a host of dissociated ionic species can arise, with a range of fluxes and masses contributing to a complex superposition of individual species IEDs. Since this situation normally represents the application focus, detailed understanding through measurement and modelling is required. Sobolewski et al [18] used a MEA along with accurate measurements of sheath voltage and ion current to study sheath dynamics in $\mathrm{CF}_{4}$ and provide the full set of input parameters required for a numerical IED model applicable across the full frequency range. Collisions in the sheath also have a significant impact on the IED. Both elastic and charge exchange (CE) collisions occur; in the former, the scatter is mostly isotropic whereas in CE collisions, fast ions transfer charge to slow neutrals resulting in slow ions and fast neutrals. In $\mathrm{rf}$ sheaths, elastic collisions reduce the energy of some ions which broadens the IED and shifts it to lower energies. CE collisions can lead to the formation of secondary peaks at significantly lower energies than the two primary peaks, the number of such peaks being almost equal to $\tau / T$ [23]. Secondary peaks can also arise due to electron impact ionization in the sheath [19] while Mizutani and Hayashi [49] concluded that $\mathrm{CE}$ could not explain observed IED peaks for $\mathrm{O}^{+}, \mathrm{CF}^{+}$and $\mathrm{CF}_{2}^{+}$ions in $\mathrm{Ar}-\mathrm{O}_{2}$ or $\mathrm{Ar}-\mathrm{C}_{3} \mathrm{~F}_{8}$ plasmas.

The difficulty of accurate IED measurement at the driven or biased electrode, the dependence on sheath voltage characteristics and the need to understand applications oriented plasma conditions involving complex chemistries and collisional processes have stimulated the modelling of $\mathrm{rf}$ sheaths and their associated IEDs. Early analytical models (e.g. [30]) were followed by numerical [52], Monte Carlo [53] and PIC [54]. More recently Dai et al used a selfconsistent fluid model to study a collisionless [55] and later a hybrid model to consider a collisional [56] sheath while Georgieva et al [57] used a PIC model coupled with Monte Carlo to investigate single and dual-frequency IEDs in complex gases under collisional conditions. For $\mathrm{Ar}-\mathrm{CF}_{4}-\mathrm{N}_{2}$ mixtures, secondary low-energy peaks on the $\mathrm{Ar}^{+}$and $\mathrm{N}_{2}^{+}$IED become increasingly prominent at higher pressures and are due to $\mathrm{CE}$ collisions whereas the $\mathrm{CF}_{3}^{+}$retains its high-energy peak with only elastic collisions, which cause a broadening of the IED on the low-energy side. The lack of CE collisions in this case is due to the low density of $\mathrm{CF}_{3}$ radicals compared with parent species. A similar effect was noted by Hallil et al [50] via measurements of a nitrogen plasma, where the molecular ion suffered CE collisions with the parent gas while the $\mathrm{N}^{+}$ion did not. Georgieva et al [57] also compared simulations with an analytical model for the dual-frequency collisionless case. Olevanov et al [58] developed an analytical approach to the dual-frequency collisionless case, at intermediate frequencies, which they compared with PIC-Monte Carlo simulations while Lee et al [59] used 1D PIC-Monte Carlo to validate an analytical model for collisionless triple frequency capacitive discharges. 


\subsection{Hydrocarbon plasmas}

IED measurements in hydrocarbon plasmas were performed for the first time using RFA by Reinke et al [38]. They measured the positive ion IEDs at the substrate position in a methane ECR plasma. The measured total flux to the surface was found to be higher by an order of magnitude than the measured carbon deposition rate. Amemiya et al [39] determined the hydrogen and hydrocarbon species distribution in methane ECR plasmas, for pressures up to $4 \mathrm{mTorr}$, and found the dominant species are $\mathrm{C}_{x} \mathrm{H}_{y}^{+}(x=1-4, y=2-6)$ but with a significant contribution from $\mathrm{H}^{+}, \mathrm{CH}_{2}^{+}$and $\mathrm{CH}_{3}^{+}$ species. Quantitative fluxes were measured in a methane dc plasma by Lange and Jacob ([86, 87] in [1]). They were the first to measure absolute fluxes of neutral $\left(\mathrm{CH}_{3}\right)$ and ionic species $\left(\mathrm{CH}_{3}^{+}\right.$and $\left.\mathrm{CH}_{4}^{+}\right)$impinging on the cathode in a pure methane plasma and showed that the integrated carbon ion flux contribution to be more than $30 \%$ of the total carbon growth rate. Ion fluxes in a dc plasma were an order of magnitude lower than in an ECR plasma. Results by Pecher and Jacob [40] for a methane ECR plasma show $\mathrm{C}_{3} \mathrm{H}_{y}^{+}$as dominant with $\mathrm{CH}_{3}^{+}$ and $\mathrm{CH}_{4}^{+}$fluxes, due to electron induced ionization of $\mathrm{CH}_{4}$, about one order of magnitude lower than $\mathrm{C}_{3} \mathrm{H}_{3}^{+}$.

Direct measurements by Tatsuta et al [21] of hydrocarbon species IED in an rf CCP and by Zhou et al [15] in an $\mathrm{Ar} / \mathrm{CH}_{4}$ molecular beam from an ICP source to a ground electrode were compared with resultant DLC film characteristics. Tatsuta, using RFA measurements (no mass selection) at the powered electrode, observed a single-peak IED at low bias and pressure. This peak evolved a low-energy shoulder as the bias was increased, possibly due to lighter species, but individual masses were not resolvable due to poor energy resolution of the analyser. As the pressure was increased to $100 \mathrm{mT}$ the single peak (as in the low bias case) spreads to a featureless and broad collisional IED at lower average energy but without secondary peaks, indicating minimal CE. Optical estimates of the sheath width at low bias vary from $\sim 15 \mathrm{~mm}$ at 20 mTorr to $\sim 2 \mathrm{~mm}$ at 500 mTorr. Correlation with DLC film properties indicated an optimal energy of the high-energy peak to produce maximum $\mathrm{sp}^{3}$ (diamond-like) bonding. Also, hydrogen content was found to reduce monotonically with ion-bombardment energy. Bauer et al [16] used a wall mounted mass spectrometer and a powered substrate MEA to sample neutrals, radical and ions in a pulsed $\mathrm{CH}_{4}$ ICP plasma and compared with resultant film properties. The energy spectra depend on the average dissipated energy per source gas molecule, but are almost independent of the ion mass and reveal narrow distributions with a FWHM of only $5 \mathrm{eV}$ due to the collisionless sheath. Their impact on film growth is considered only in terms of the flux of $\mathrm{C}$ - or H-carrying species to the film. Zhou et al [15] observed mass-selected IEDs of (in approximate order of abundance) $\mathrm{CH}_{3}^{+}, \mathrm{ArH}^{+}, \mathrm{Ar}^{+}, \mathrm{H}_{3}^{+}$and $\mathrm{H}^{+}$plus other $\mathrm{C}_{x} \mathrm{H}_{y}^{+}$, ions at 40 mTorr. For conditions where $\mathrm{CH}_{3}^{+}$and $\mathrm{ArH}^{+}$ species display single-peaked, narrow IEDs, $\mathrm{Ar}^{+}$indicates some secondary CE peaks, as does $\mathrm{H}^{+}$; the hydrogen ion IEDs indicate development of a bimodal structure; the lightest $\mathrm{C}_{x} \mathrm{H}_{y}^{+}$ IED displays a developing low-energy shoulder. Across the power and pressure range measured, the mean bombardment energy of the $\mathrm{CH}_{3}^{+}$ion was greater than that of $\mathrm{Ar}^{+}$by up to a factor of 3. Values of film hardness and Young's modulus reached a maximum at $\sim 100 \mathrm{eV}$, with an estimated average IE of $20 \mathrm{eV}$, and dropped at higher biases. However, direct correlation with the IEDs was not possible due to the distance of the MEA from the substrate location. More recently Ikkurthi et al [60] used a 1D PIC model to investigate ion transfer optics and the modulation effects of the potential between the aperture and ion extractor lens on the interpretation of measured IEDs at the powered electrode. Mass-selective IEDs were obtained in an asymmetric $\mathrm{CCP}$ system for $\mathrm{Ar}-\mathrm{CH}_{4}$ mixtures with self-bias voltages of 400-500 V, providing one of the very few examples where such IEDs are measured at the powered electrode. Computed $\tau / T$ ratios vary from $\sim 1\left(\mathrm{H}^{+}\right)$to over 6.5 for $\mathrm{Ar}^{+}$ or $\mathrm{ArH}^{+}$while for $\mathrm{CH}_{3}^{+}$it is 4.27. CE peaks were observed for $\mathrm{Ar}^{+}$(but not $\mathrm{ArH}^{+}$) and $\mathrm{CH}_{4}^{+}$with elastic collisions also in evidence in the latter. Experimental and simulation results agree qualitatively in the number of secondary peaks but not their location. There was also disagreement between simulated and experimental values of peak energy values, especially for $\mathrm{H}_{2}^{+}$. These discrepancies are attributed, as in $[36,51]$, to the rf potential variation between the powered electrode orifice and the MEA which modulates the IE similarly to the well-known effect of rf sheath modulation. Here, however, the modulation depends on $\tau_{\mathrm{MEA}} / T$ where $\tau_{\mathrm{MEA}}$ is the ion flight time across the gap between orifice and lens/extractor. This modulation will therefore be more prominent with lighter ions, shorter gaps and lower frequencies. It will also have greater impact on fast ions coming through the orifice. In this work, our gap is $30 \mathrm{~mm}$ compared with $2 \mathrm{~mm}$ in [36] and a simulated value of $25 \mathrm{~mm}$ in [60]; compared with the latter our (ICP) energies are much lower at $100 \mathrm{eV}$ compared with $500 \mathrm{eV}$.

The aim of this work therefore is to investigate the use of in situ plasma diagnostics under realistic DLC process conditions, to gain an understanding of the plasma conditions that have significance in DLC deposition and to explore options to expand the process parameter space. To this end we have used mass spectrometry and mass-selected ion spectrometry at the rf-biased substrate electrode to determine neutral and ion fluxes in an ICP reactor, along with infra-red absorption studies for temporal neutral species evolution after argon-acetylene plasma initiation. These results are presented in an associated paper [4]. In this paper, IEDs for $\mathrm{Ar}^{+}$and the dominant $\mathrm{H}_{x} \mathrm{C}_{y}^{+}$ species are determined at the biased substrate for various values of mean rf bias, bias frequency, pressure and $\mathrm{Ar} / \mathrm{C}_{2} \mathrm{H}_{2}$ flow ratios. For comparison, IEDs are also measured in a $\mathrm{CCP}$ system that has been routinely used for DLC deposition. In this case, access for the mass-energy spectrometer is only available at the grounded chamber wall. Species flux data are compared with previously reported spectra taken at remote locations from the substrate for use in subsequent plasma models. Deposited film properties are evaluated under a range of bias and pressure conditions in order to derive guiding principles for process optimization in terms of mean IE and IE spread and their relationship to bias voltage and frequency, pressure and gas flow ratio. Film characteristics are compared with those obtained by other techniques (CCP PECVD, cathodic arc and sputtering) in order to gain insight into possible growth mechanisms. 


\section{Experimental}

The measurements described in this study were performed in two rf-driven plasma facilities, one employing a CCP and the other an ICP. The working gases were usually pure argon or $2: 1$ $\mathrm{C}_{2} \mathrm{H}_{2}$ : Ar mixtures; a small number of measurements made with other flow ratios are noted in the text.

\subsection{Capacitively coupled plasma}

The CCP comprised a $360 \mathrm{~mm}$ diameter $480 \mathrm{~mm}$ tall cylindrical chamber attached to associated gas, vacuum and electrical supplies, figure 1(a). Gas flow controllers were used to set the flow rates (and thus flow ratios) of the working gases over the pressure range studied. A $13.56 \mathrm{MHz}$ rf power supply and matching network was used to apply an rf potential to the $270 \mathrm{~mm}$ diameter driven (substrate) electrode, sited centrally at the base of the chamber. To measure the IED, the chamber was adapted to house a HIDEN EQP 300 massenergy analyser (MEA), which was sited at the side wall of the chamber, $170 \mathrm{~mm}$ above the top face of the driven electrode. The analyser was operated in IE mode to give the IED. The measurements were made at $12 \mathrm{mTorr}$ CCP dc bias $\left(V_{\mathrm{dc}}\right)$ of $450 \mathrm{~V}$.

\subsection{Inductively coupled plasma}

The ICP chamber, figure $1(b)$, is a $400 \mathrm{~mm}$ diameter sphere with six orthogonal $250 \mathrm{~mm}$ diameter ports which provide access for plasma systems and diagnostics. Needle valves were used to set the flow rates and ratios of the working gases within a pressure range $3.3-120 \mathrm{mTorr}$. The $13.56 \mathrm{MHz}$ rf power supply and close coupled automatic matching network drive an rf current through the water cooled $152 \mathrm{~mm}$ diameter flat spiral ICP coil, which has four lobes to inhibit E-mode operation. The oscillating rf current in the coil couples to the plasma via a $12.5 \mathrm{~mm}$ thick quartz window below which a $120 \mathrm{~mm}$ diameter substrate electrode is sited. The window to electrode separation was $160 \mathrm{~mm}$ for all measurements. A second, variable frequency $\left(f_{\text {bias }}\right)$, rf power supply and matching network were used to apply a negative bias $\left(V_{\text {bias }}\right)$ to the substrate electrode. The substrate electrode was coupled, via a central $50 \mu \mathrm{m}$ diameter hole, to the MEA, which was operated in IE mode. A Scientific Systems compensated Langmuir probe was used to measure plasma parameters $107 \mathrm{~mm}$ above the bias electrode, at a radius of $45 \mathrm{~mm}$ from the vertical axis. Under steady-state conditions calculated values of electron density were $4 \times 10^{16} \mathrm{~m}^{-3}$ and $2 \times 10^{16} \mathrm{~m}^{-3}$ for Ar and $\mathrm{Ar}: \mathrm{C}_{2} \mathrm{H}_{2}(1: 2)$, respectively, while estimated values for electron temperature and plasma potential also showed a fall from $\sim 3.5 \mathrm{eV}$ to $\sim 3.3 \mathrm{eV}$ and from $22 \mathrm{~V}$ to $20 \mathrm{~V}$, respectively, once acetylene was added to argon. Further details are given in the associated paper [4].

This study concentrates on the IED at the biased electrode with varying pressures, $V_{\text {bias }}, f_{\text {bias }}$ and on DLC deposition at 3.3 mTorr. In most cases the ICP input power was set at $200 \mathrm{~W}$ and automatically matched so that the reflected power was $<1 \mathrm{~W}$. The working gases were again pure argon or $2: 1 \mathrm{C}_{2} \mathrm{H}_{2}:$ Ar.
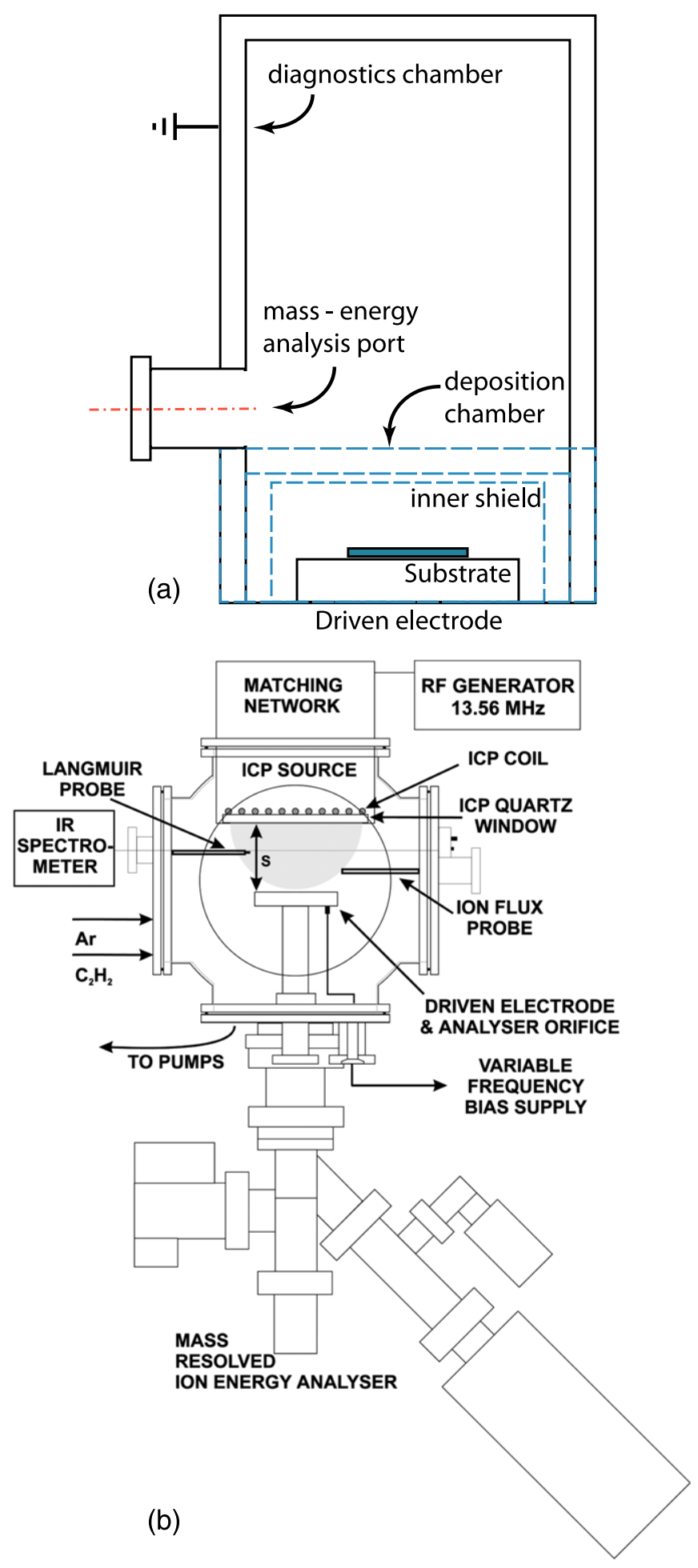

Figure 1. (a) CCP chamber for mass-energy measurements. In deposition mode, the tall chamber is replaced by a shorter chamber and an inner shield, illustrated by dashed lines. (b) ICP chamber and diagnostics schematic diagram.

DLC (a-C:H) films were deposited on silicon samples placed on the rf-biased electrode. Samples $\left(10 \times 10 \mathrm{~mm}^{2}\right)$ were cleaned using deionized water and ultrasonic treatment before loading into the vacuum chamber. The samples were further cleaned using $\mathrm{Ar}^{+}$ion sputter at $3.3 \mathrm{mTorr}$ and $100 \mathrm{~V}$ bias voltage, prior to deposition. The depositions were performed 


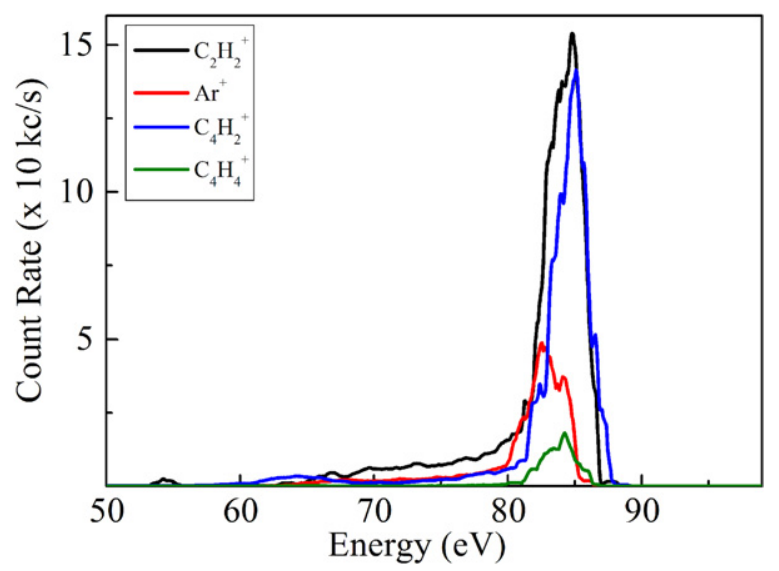

Figure 2. IEDs of four dominant species measured at the wall in the CCP: 12 mTorr $^{\mathrm{C}_{2} \mathrm{H}_{2}}$ : Ar (flow ratio $2: 1$ ), $V_{\mathrm{dc}}=450 \mathrm{~V}$ at $13.56 \mathrm{MHz}$.

at 3.3 mTorr working pressure, for a range of bias voltages 7 to $100 \mathrm{~V}$ at $8.311 \mathrm{MHz}$ bias frequency using $33 \%$ argon in $\mathrm{C}_{2} \mathrm{H}_{2}$ : Ar. Film thicknesses were measured using a Dektak stylus profilometer and surface characterization was done using ISA LabRam Raman and Nanoindentation.

\section{Results}

\subsection{Ion energy distribution}

For the CCP configuration, IEDs of the main positive species $\left(\mathrm{Ar}^{+}, \mathrm{C}_{2} \mathrm{H}_{2}^{+}\right.$) as well as those for $\mathrm{C}_{4} \mathrm{H}_{2}^{+}$and $\mathrm{C}_{4} \mathrm{H}_{4}^{+}$are shown in figure 2, for constant bias $(450 \mathrm{~V})$ and pressure (12 mTorr). All species show a similar energy distribution with a dominant single peak at around $84 \mathrm{~V}$, indicating the ions transit the sheath in response to the time-averaged rf sheath voltage, which varies little with applied substrate bias. For example, the $\mathrm{Ar}^{+}$peak energy increased by $\sim 15 \%$ for a bias reduction of $350 \mathrm{~V}$. Secondary peaks which are evidence of CE collisions within sheath $[19,23]$ are detectable at lower energies of $50-60 \mathrm{eV}$, with 1-2 orders of magnitude lower count rates. These IEDs therefore are not truly representative of the ion arrival energies at the substrate.

The ICP configuration allows the spectrometer head to be incorporated into the substrate electrode and driven at the same bias voltage and frequency. For a fixed ICP input power of $200 \mathrm{~W}$ at $13.56 \mathrm{MHz}$, with constant bias frequency (8.311 MHz) and pressure (3.3 mTorr), the dominant positive ions $\mathrm{Ar}^{+}, \mathrm{ArH}^{+} \mathrm{C}_{2} \mathrm{H}_{2}^{+}$and $\mathrm{C}_{4} \mathrm{H}_{2}^{+}$account for $\sim 91.5 \%$ of ion flux across the energy range $0-200 \mathrm{eV}$. Figure 3 shows the IEDs of each of these species for a range of negative dc bias voltages up to $100 \mathrm{~V}$. Count rates have been normalized to the value for $\mathrm{Ar}^{+}$at that bias and bias voltage sets are shifted vertically for clarity. Also shown are IEDs for a number of other species $\left(\mathrm{C}_{2} \mathrm{H}^{+}, \mathrm{CH}_{3}^{+}, \mathrm{C}_{2} \mathrm{H}_{4}^{+}\right)$with normalized count rates scaled by a factor of 5. For each species a bimodal energy peak structure is observed, with a mean energy that increases with bias and an energy width $(\Delta E)$ that decreases with increasing mass. For each bimodal distribution, the ratio $(I)$ of high-energy to lowenergy peak heights is $<1$ except for the lowest bias $(-7 \mathrm{~V})$.

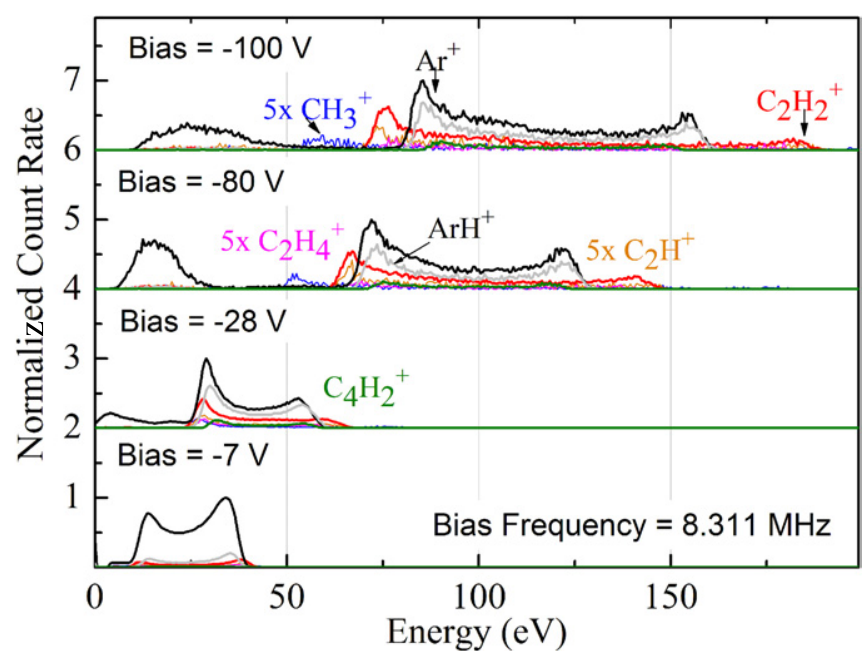

Figure 3. IEDs of seven dominant species at the biased electrode of the ICP: 3.3 mTorr $\mathrm{C}_{2} \mathrm{H}_{2}: \mathrm{Ar}$ (flow ratio $2: 1$ ) $f_{\text {bias }}=8.311 \mathrm{MHz}$ and $V_{\text {bias }}$ varied. For clarity some ion fluxes are multiplied by 5 and shifted vertically.

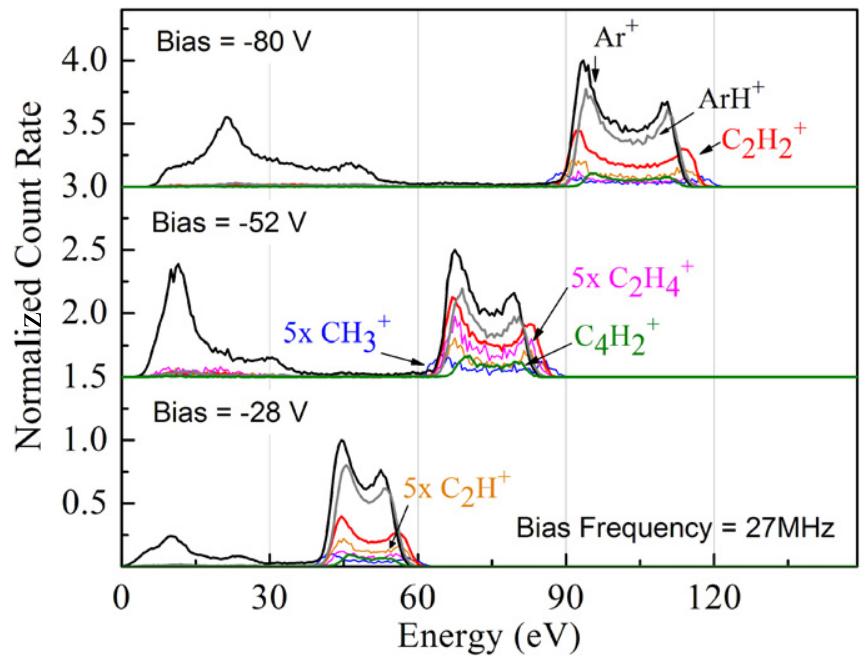

Figure 4. IEDs of seven dominant species at the biased electrode of the ICP: 3.3 mTorr $\mathrm{C}_{2} \mathrm{H}_{2}:$ Ar (flow ratio $2: 1$ ) $f_{\text {bias }}=27 \mathrm{MHz}$ and $V_{\text {bias }}$ varied. For clarity some ion fluxes are multiplied by 5 and shifted vertically.

The $\mathrm{Ar}^{+}$IED also contained an additional broad peak at low energy $(5-25 \mathrm{eV})$, the exact position of which depends on bias voltage.

In figure 4, IEDs for the same species are again plotted for varying bias, in this case for a high bias frequency $(27 \mathrm{MHz})$ and similar characteristics are observed but with a significant reduction in $\Delta E$ as the ratio of ion transit time to $\mathrm{rf}$ period $(\tau / T)$ approaches the high-frequency limit [33], discussed later. At higher pressure ( 25 mTorr), the bimodal peaked structure is preserved, figure 5. However, the dominant ion is now $\mathrm{ArH}^{+}$, mainly at the expense of the $\mathrm{Ar}^{+}$. The effect of changing the argon-acetylene flow ratio on the IEDs of the $\mathrm{Ar}^{+}$and $\mathrm{C}_{2} \mathrm{H}_{2}^{+}$ion species is shown in figure 6. The data are obtained at low bias voltage and at a constant bias frequency $(8.311 \mathrm{MHz})$ and pressure (3.3 mTorr). For both ion species, increasing the $\mathrm{Ar}: \mathrm{C}_{2} \mathrm{H}_{2}$ flow ratio results in an increase in $\Delta E$, 


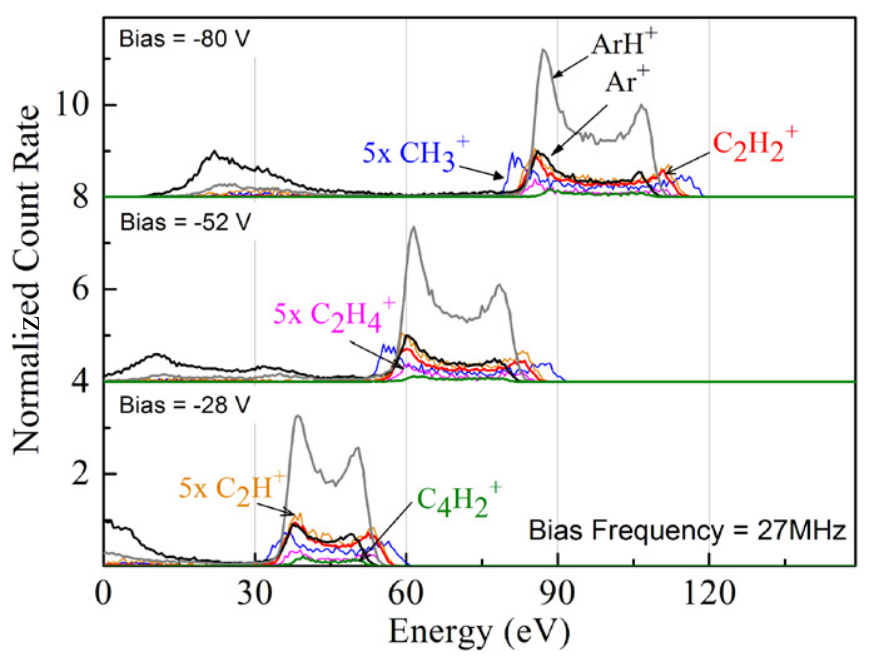

Figure 5. IEDs of seven dominant species at the biased electrode of the ICP: 25 mTorr $\mathrm{C}_{2} \mathrm{H}_{2}: \mathrm{Ar}$ (flow ratio $2: 1$ ) $f_{\text {bias }}=27 \mathrm{MHz}$ and $V_{\text {bias }}$ varied. For clarity some ion fluxes are multiplied by 5 and shifted vertically.

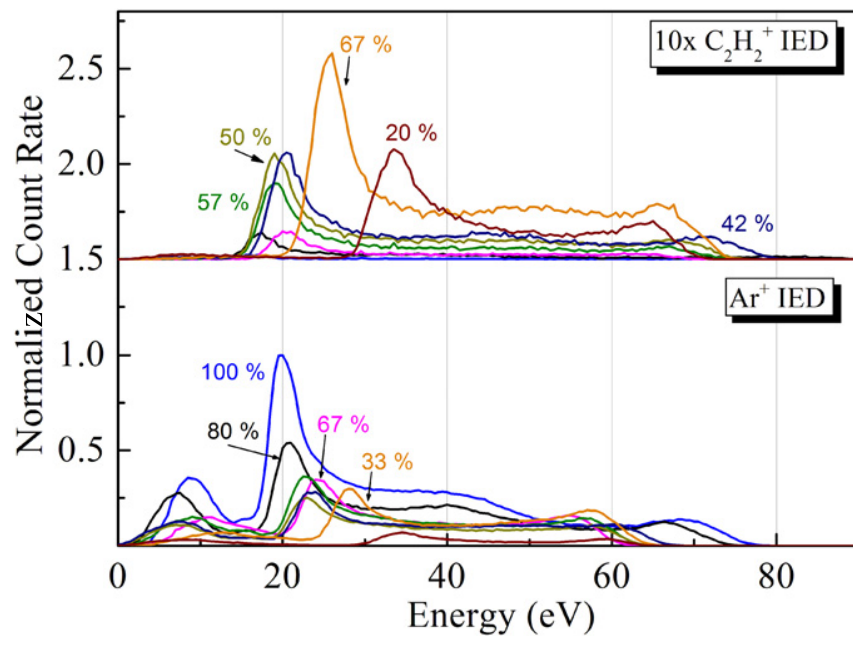

Figure 6. IEDs of $\mathrm{Ar}^{+}$and $\mathrm{C}_{2} \mathrm{H}_{2}^{+}$for varying argon fractions (marked on figure) measured at the biased electrode of the ICP:

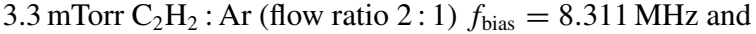
$V_{\text {bias }}=28 \mathrm{~V} . \mathrm{C}_{2} \mathrm{H}_{2}^{+}$IED vertically shifted and scaled 10 times for clarity.

mainly due to a decrease in the position of the low-energy peak. The peak height ratio, I, also decreases such that at $100 \% \mathrm{Ar}$, the IED consists mainly of a single low-energy peak.

IEDs have also been obtained at pressures (20 and 120 mTorr) for zero and high bias values and are shown in figure 7 . The figure shows only the $\mathrm{Ar}^{+}$ion but similar IEDs are obtained for hydrocarbon ions with greatly reduced flux.

\subsection{Film deposition}

Mass and IE spectrometry has been carried out in our film deposition chambers and in this section we present results on hydrogenated amorphous carbon $(\mathrm{a}-\mathrm{C}: \mathrm{H})$ film characteristics deposited under similar process conditions. PECVD of a-C:H films is most commonly carried out in standard parallel plate CCP systems and hence we simply

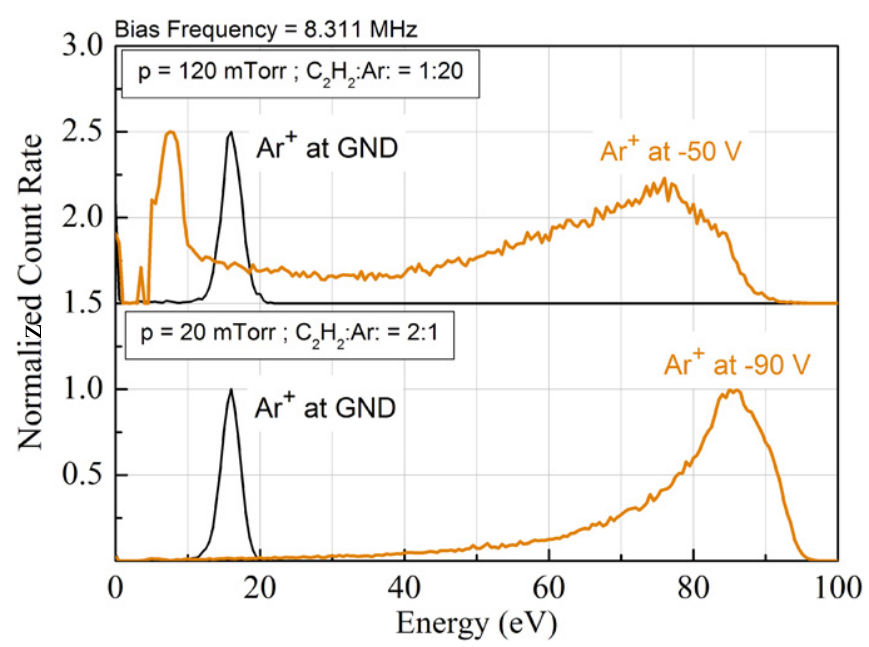

Figure 7. IEDs of $\mathrm{Ar}^{+}$ion measured at the biased electrode of the ICP for two pressures and $V_{\text {bias }}$ varied at $f_{\text {bias }}=8.311 \mathrm{MHz}$ with different flow ratios of $\mathrm{C}_{2} \mathrm{H}_{2}$. : Ar. For clarity IEDs for $120 \mathrm{mTorr}$ are shifted vertically upwards.

report relevant results carried out in the same chamber as the spectrometry, from our previous publications [5-9]. It should be noted, however, that the chamber required modification to accommodate the spectrometer head, resulting in an increase in the cathode-anode separation from $6 \mathrm{~cm}$ (deposition) to $16 \mathrm{~cm}$. A number of films deposited under the latter configuration underwent rudimentary analysis and were found to be similar in quality to those obtained with the normal configuration. ICP deposition of a-C: $\mathrm{H}$ has received only limited attention to date and since in this configuration substrate bias variation is possible independent of plasma generation, we concentrate on this aspect of film deposition. Since the spectrometer head is incorporated within the substrate electrode, species measurement and deposition conditions are the same. However, simultaneous measurement and deposition were not undertaken in order to control film thickness and minimize carbon loading of the internal spectrometer electrodes. Thus the orifice was closed during deposition. Determination of a-C: $\mathrm{H}$ film structure $\left(\mathrm{sp}^{3} / \mathrm{sp}^{2}\right.$ bonding and hydrogen content) and properties involves a number of detailed high resolution materials analysis techniques. A detailed review of amorphous carbon growth, deposition techniques, materials analysis and film properties, including hydrogenated films, is given by Robertson [26] and also by Jacob [1]. For this work, however, we are interested in relative changes in structure and hence we use features of the measured Raman spectra as indicators. We also made hardness measurements using nanoindentation at an approximately constant film thickness in order to obtain more direct indication of relative film quality under different conditions. More detailed materials analysis and film optimization will be the subject of a future publication. Finally, we compare these results for a-C:H with our previously published work on hydrogen-free amorphous carbon films deposited via filtered cathodic vacuum arc and unbalanced magnetron sputtering techniques.

For a deposition time of $60 \mathrm{~s}$, figure 8 shows the resultant film thickness variation with substrate bias for constant bias 


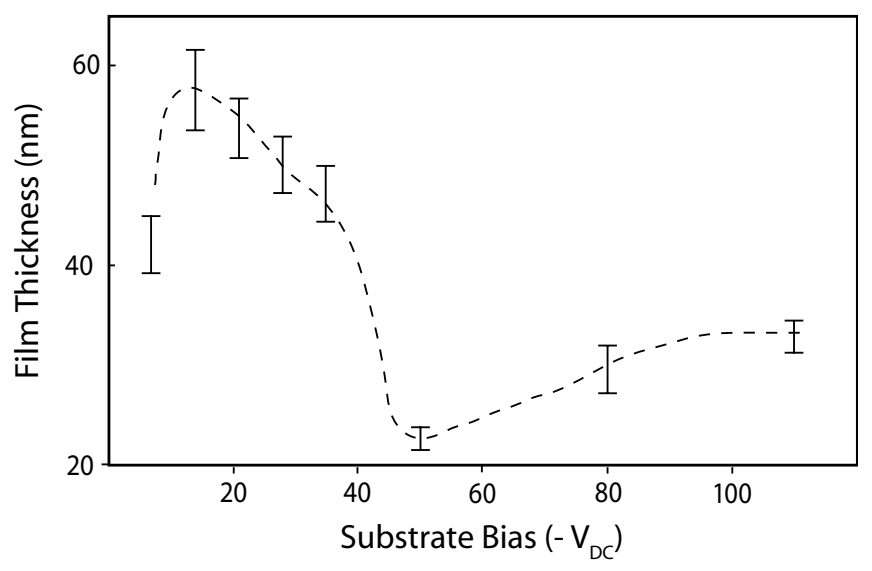

Figure 8. DLC film thickness versus substrate bias in the ICP: $3.3 \mathrm{mTorr}_{2} \mathrm{H}_{2}: \mathrm{Ar}=2: 1, f_{\text {bias }}=8.311 \mathrm{MHz}$.
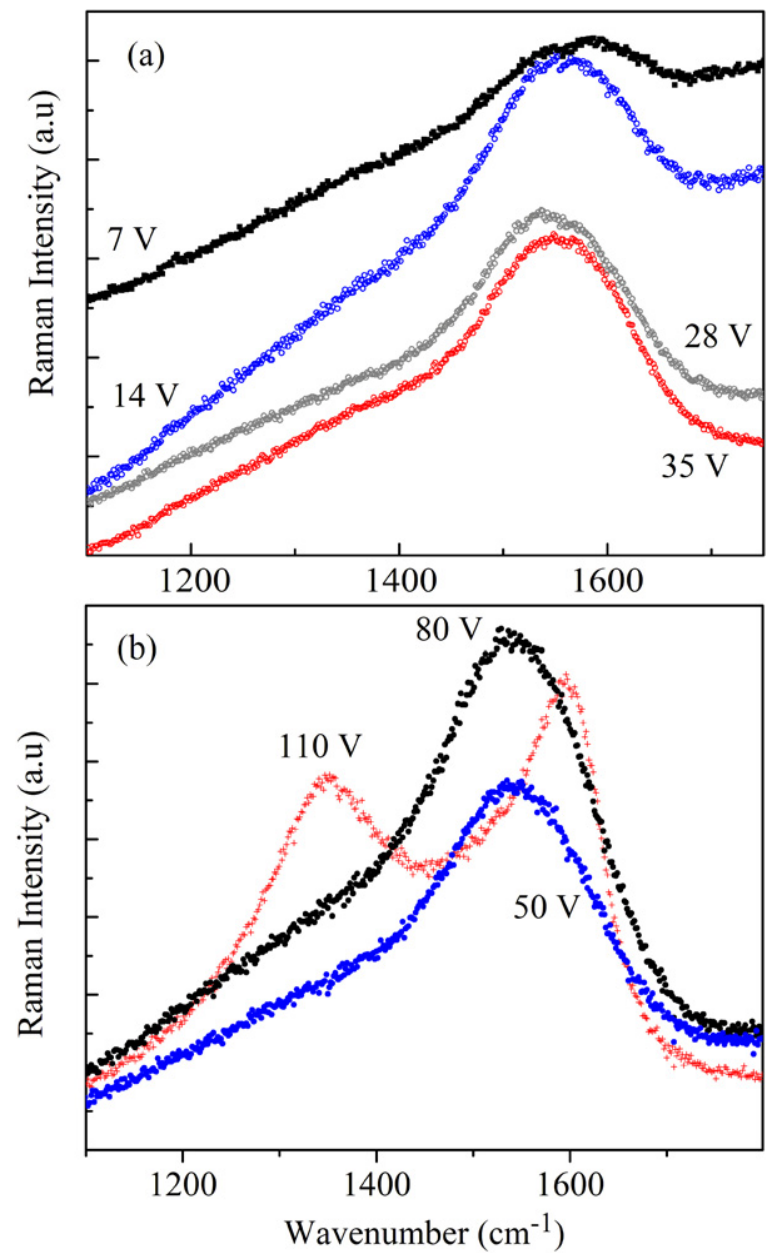

Figure 9. Raman spectra obtained for samples at each bias deposited in the ICP: 3.3 mTorr, $\mathrm{C}_{2} \mathrm{H}_{2}: \mathrm{Ar}=2: 1$, $f_{\text {bias }}=8.311 \mathrm{MHz}$. (a) $V_{\text {bias }}(7 \mathrm{~V}$ to $35 \mathrm{~V})(b) V_{\text {bias }}(50 \mathrm{~V}$ to $100 \mathrm{~V})$.

frequency $(8.311 \mathrm{MHz})$, pressure $(3.3 \mathrm{mTorr})$, gas flow ratio $\left(\mathrm{C}_{2} \mathrm{H}_{2}: \mathrm{Ar}=2: 1\right)$ and ICP power $(200 \mathrm{~W})$. The thickness is seen to drop significantly for bias voltages over $40 \mathrm{~V}$.

In figure 9, the Raman spectra for each film show the characteristic peak at $\sim 1550 \mathrm{~cm}^{-1}$ (G-peak). Double Gaussian deconvolution of the spectra enables detection of a second peak

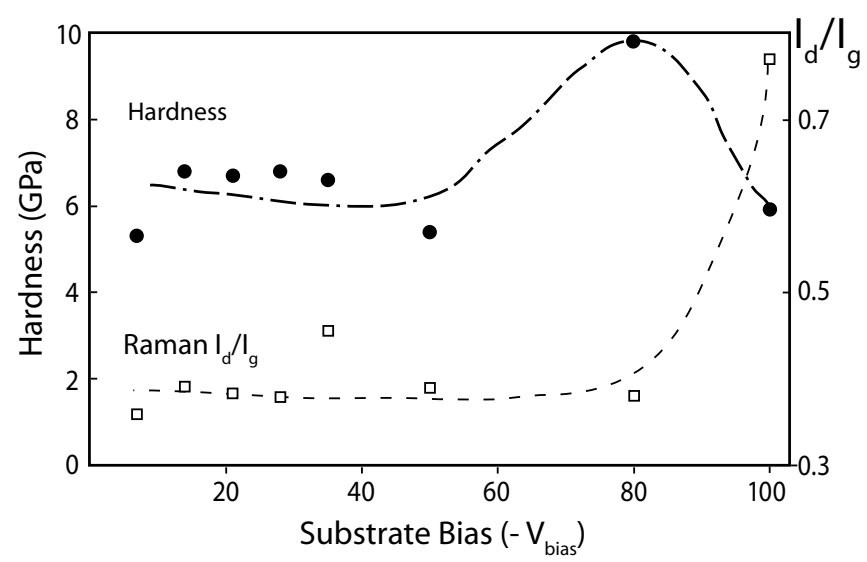

Figure 10. Hardness and $I_{\mathrm{D}} / I_{\mathrm{G}}$ ratio versus substrate bias for the DLC samples deposited in the ICP: 3.3 mTorr $_{2} \mathrm{H}_{2}: \mathrm{Ar}=2: 1$, $f_{\text {bias }}=8.311 \mathrm{MHz}$.

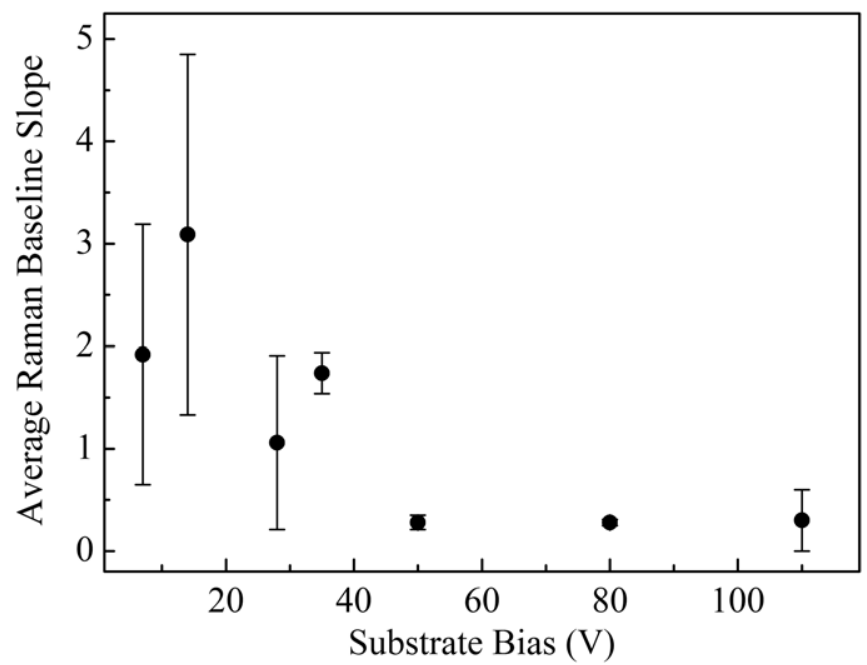

Figure 11. Slope of Raman spectra extracted using graph depicted in figure 9 .

at approximately $1380 \mathrm{~cm}^{-1}$ (D-peak) from which the ratio of peak heights $I_{\mathrm{D}} / I_{\mathrm{G}}$ can be determined. This ratio is a useful indicator of the $\mathrm{sp}^{2} / \mathrm{sp}^{3}$ carbon-carbon bonding ratio provided the hydrogen content is relatively low. Ratios of 0.4 and lower are indicative of hard DLCs. Figure 10 shows the $I_{\mathrm{D}} / I_{\mathrm{G}}$ ratio to be $\sim 0.4$ for all films except for the highest bias. For soft films with a large hydrogen content, however, a low $I_{\mathrm{D}} / I_{\mathrm{G}}$ ratio can also be observed. Hydrogen content is difficult to estimate but it can give rise to significant luminescence under laser excitation and results in a noticeable slope in the Raman spectra [10]. Figure 11 shows the baseline slope of the spectra of figure 9 , calculated in the regions from $500-1000 \mathrm{~cm}^{-1}$ to $1700-2200 \mathrm{~cm}^{-1}$. At low biases the slope is high but falls to almost zero for biases above $\sim 40 \mathrm{~V}$. A high hydrogen content at low bias is consistent with the greater growth rate observed under these conditions as the film density can be expected to be lower.

Film hardness was obtained from nanoindentation measurements and is also shown in figure 10. Here we observe a clear peak in hardness at a bias of $80 \mathrm{~V}$. It should be noted that for very thin films $(\sim 30-60 \mathrm{~nm})$, the extracted hardness value 


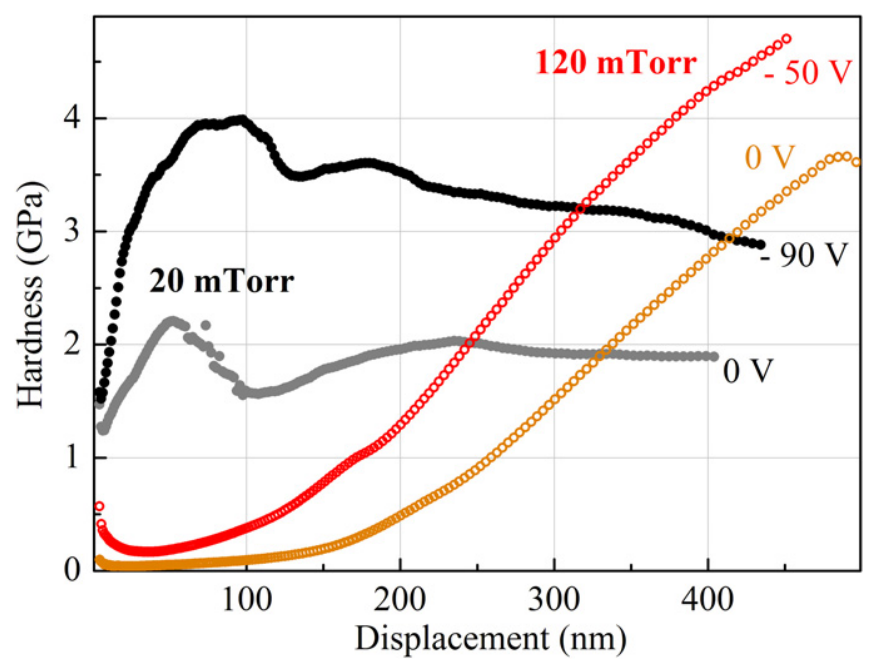

Figure 12. Hardness versus displacement for the DLC films in the

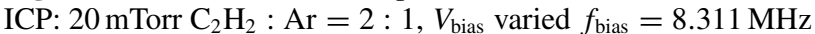
and $120 \mathrm{mTorr}_{2} \mathrm{C}_{2} \mathrm{H}_{2}: \mathrm{Ar}=1: 20, V_{\text {bias }}$ varied $f_{\text {bias }}=8.311 \mathrm{MHz}$.

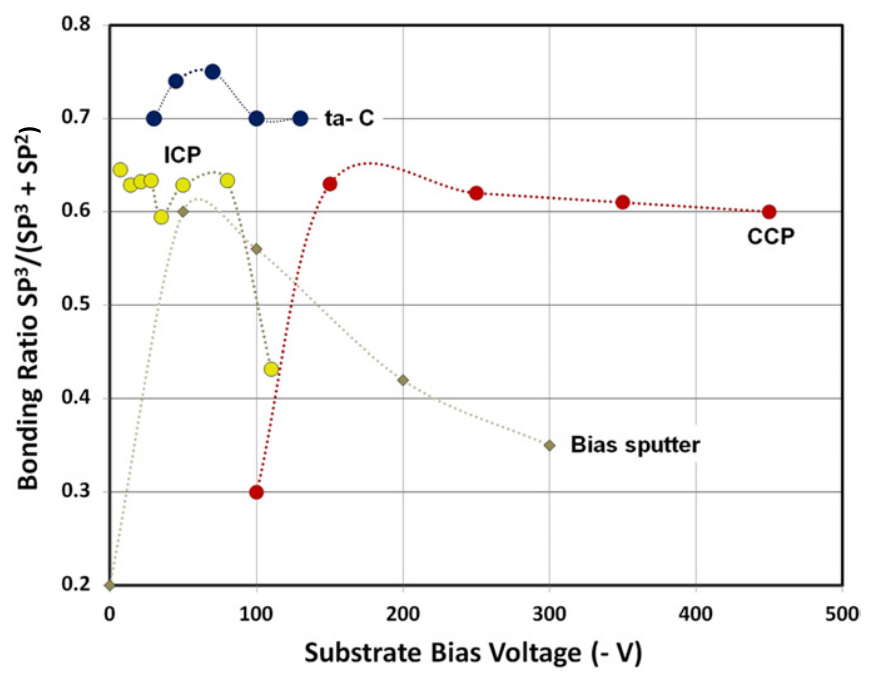

Figure 13. Comparison of estimated $\mathrm{sp}^{3}$ bonding ratio in ICP-deposited DLC (a-C : $\mathrm{H})$ samples with films previously deposited via (i) CCP (a-c: H), in [5-9], and (ii) non-hydrogenated DLC deposited via filtered cathodic vacuum arc (FCVA), in [10,11], and via biased unbalanced magnetron sputtering, in [12,13].

depends on a number of factors such as penetration depth, tip blunting and the influence of the underlying substrate. For these measurements we used a fixed nanoindentation protocol and a constant penetration depth throughout in order to ensure that relative hardness values are reliable. More detailed analysis is currently in progress.

Hardness measurements were also obtained from films deposited at pressures of 20 mTorr and 120 mTorr for both zero and high bias values of $50 \mathrm{~V}$ and $90 \mathrm{~V}$, respectively, figure 12 , and it can be seen that the influence of the bias is still evident. The actual hardness is sensitive to tip displacement into the film and overall, as expected, these films are softer than those obtained at 3.3 mTorr, with a much higher growth rate and lower density. Nevertheless, these films are still much harder than thin polymer-like films.
Finally, the properties of the ICP-deposited films are compared with our previous results for CCP deposited a-C : $\mathrm{H}$ [5-9] and with hydrogen-free films ta-C $[10,11]$ and bias-sputtered films [12,13], figure 13. These data are representative of the general film properties of amorphous carbons reported in the literature $[1,26,27] . I_{\mathrm{D}} / I_{\mathrm{G}}$ ratios are not directly comparable across hydrogenated and non-hydrogenated films and therefore the ICP ratios are equated to $\mathrm{sp}^{3}$-fraction using conversion factors determined previously from detailed analysis of CCP films. The influence of substrate bias on the $\mathrm{sp}^{3}$-fraction shows a similar trend for ICP a-C : $\mathrm{H}$ and non-hydrogenated samples, with a reduction beyond $50-100 \mathrm{~V}$, whereas for CCP samples, the maximum $\mathrm{sp}^{3}$-fraction is not obtained below biases of $\sim 200 \mathrm{~V}$, whereupon it remains constant up to $\sim 500 \mathrm{~V}$. Note that the hydrogen contribution to $\mathrm{sp}^{3}$ content has not been excluded in the case of ICP samples and hence the carbon $\mathrm{sp}^{3}$-fraction is likely to be overstated, particularly at lower biases where the films are softer.

\section{Discussion}

\subsection{Ion energy distribution}

We have measured IEDs for both CCP and ICP configurations. In the former the distribution, as measured on the grounded chamber wall, is dominated by a single peak for each of the four main species, $\mathrm{C}_{2} \mathrm{H}_{2}^{+}, \mathrm{C}_{4} \mathrm{H}_{2}^{+}, \mathrm{Ar}^{+}, \mathrm{C}_{4} \mathrm{H}_{4}^{+}$, centred around $84 \mathrm{eV}$ for a substrate bias of $450 \mathrm{~V}$. The dominant ion is $\mathrm{C}_{2} \mathrm{H}_{2}^{+}$, most likely formed by direct ionization of the parent molecule $(11.4 \mathrm{eV})$ rather than $\mathrm{CE}$ with $\mathrm{Ar}^{+}\left(10^{-16} \mathrm{~m}^{3} \mathrm{~s}^{-1}\right)$ [14]. The $\mathrm{C}_{4} \mathrm{H}_{2}^{+}$ion displays a similar level of flux to $\mathrm{C}_{2} \mathrm{H}_{2}^{+}$. In ICP generated IEDs we observe, at low pressure and mid-frequency (8.311 MHz), a different ordering of ion species with $\mathrm{Ar}^{+}$being dominant, followed by $\mathrm{ArH}^{+}$then $\mathrm{C}_{2} \mathrm{H}_{2}^{+}$. The flux of radical ions $\mathrm{C}_{2} \mathrm{H}^{+}$and $\mathrm{CH}_{3}^{+}$has greater prominence compared with the CCP case, although still 1-2 orders of magnitude lower than $\mathrm{Ar}^{+}$. The flux of $\mathrm{C}_{4} \mathrm{H}_{2}^{+}$is now almost negligible.

In an associated paper [4], we observed that one of the dominant processes in $\mathrm{C}_{2} \mathrm{H}_{2}$ : Ar plasmas involves hydrogen abstraction from the parent $\mathrm{C}_{2} \mathrm{H}_{2}$ molecule, via electron dissociative bombardment. This results in a pressure drop and a reduction in the set $\mathrm{C}_{2} \mathrm{H}_{2}$ : Ar flow ratio. In general, an ICP is known to have electron densities typically 1-2 orders of magnitude greater than CCPs for similar power inputs. Furthermore, electron energy distribution functions (EEDFs) measured in the ICP indicate a greater proportion of electrons of intermediate energy $(3-18 \mathrm{eV})[4,15]$ compared with the bi-Maxwellian EEDFs expected in CCPs. Thus, in a pure argon plasma the ICP configuration has the greater $\mathrm{Ar}^{+}$density, compared with $\mathrm{CCP}$, for equivalent power density. In the $\mathrm{C}_{2} \mathrm{H}_{2}$ : Ar ICP plasma conditions therefore favour electron dissociation over ionization of acetylene to a much greater degree than for the CCP. Thus the lower observed $\mathrm{C}_{2} \mathrm{H}_{2}^{+}$ion flux in the ICP is to be expected.

From a materials deposition perspective, the nature of the ion flux is important. Current models [1] assume a dominant carbon-carrying ion flux which contributes to growth via direct incorporation of carbon (as well as hydrogen) ions into the 
growing film. The energy of the carbon ions is thought to be important in determining the final bonding $\left(\mathrm{sp}^{3} / \mathrm{sp}^{2}\right)$ and hydrogen content. For ICP-deposited films, however, the flux of carbon-carrying ions is extremely small and the energetics of growth is therefore dominated by inert argon (or $\mathrm{ArH}^{+}$) bombardment.

Growth of hydrocarbon films is a complex function of both synergistic and competing reactions. In its simplest form, this growth involves (i) direct incorporation of radical dissociation products of the precursor $\left(\mathrm{C}_{2} \mathrm{H}_{2}\right)$, which depends on their sticking coefficient, (ii) direct incorporation of secondary reaction products of relatively high sticking coefficient, particularly the higher hydrocarbons, (iii) indirect incorporation of primary dissociation or secondary reaction products via surface dangling bond activation involving ion bombardment and/or atomic hydrogen reactions, (iv) direct incorporation of energetic carbonaceous ions and (v) reduction of film hydrogen content via ion bombardment or film etching by atomic hydrogen. Investigation of the dominance of the different reaction channels is hampered by the limited data on plasma species, flux and energies involved. A number of dedicated experiments, for example, involving pure radical beams [2], pulsed plasma [16] and remote ECR plasma sources [1] have been undertaken to elucidate the various reaction channels. These have concentrated mainly on the radical-based channels while ion-bombardment reactions, especially at energies normally found in plasma deposition, have received much less attention. In this work, we observe a distinct hardness-bias relationship for the ICP films where $\mathrm{Ar}^{+} / \mathrm{C}_{2} \mathrm{H}_{2}^{+} \gg 1$ while for CCP films, where $\mathrm{Ar}^{+} / \mathrm{C}_{2} \mathrm{H}_{2}^{+} \ll 1$, the bias voltages are much greater $(>150 \mathrm{~V})$ and the bias dependence is minimal above a threshold. However, such a straightforward comparison does not account for the different distribution (IED) of ion energies at the substrate. In terms of IED shape, we observe a distinct difference between the singlepeaked structures obtained from the CCP compared with the bimodal peaked ICP distributions. In the latter case, a third low-energy $\mathrm{Ar}^{+}$peak was often observed, possibly due to collisions, while the exact features of the bimodal structure depended on bias and frequency. Since the CCP measurement is made at the wall, however, it is not clear whether the single peak is truly representative of the IED at the substrate.

The shape of an IED, from simple analytical models, is expected to exhibit bimodal peaks with the width of the distribution varying as a function of ion mass, $\mathrm{rf}$ voltage and frequency. At sufficiently high frequency, the ratio of ion transit time to $\mathrm{rf}$ period is long and the ion sees effectively a dc potential, leading to a single-peak IED. $\mathrm{Ar}^{+}$IED models by Economou [17] show a double peak at $13.56 \mathrm{MHz}$, while both models and measurements by Sobolewski et al [18] show a single-peak distribution only at higher frequencies $(30 \mathrm{MHz})$ for $\mathrm{CF}_{4}$ derived species in an ICP discharge. The latter was measured at the grounded chamber wall and the observed IED was related to that at the driven electrode through bias-induced variation in the plasma potential. While these models and results relate particularly to high density ICP systems, other reports for CCP operation also show bimodal distributions $[19,20]$ for IEDs measured at the driven substrate.
However, IED measurements by Tatsuta [21] under rf-biased conditions showed, for both $\mathrm{Ar}^{+}$and $\mathrm{CH}_{4}^{+} \mathrm{CCP}$ plasmas, a dominant single peak situated at energies $\geqslant V_{\text {bias }}$ and a smaller 'collisional' peak at lower energies. For similar measurements at the ground electrode, this single peak was less pronounced, while the 'collisional' peak had broadened. For a $13.56 \mathrm{MHz}$ $\mathrm{Ar} / \mathrm{CH}_{4}$ plasma, Zhou et al [15] observed single-peak IED characteristics as did Jacob [1]. These were obtained at a grounded electrode remote from an ICP or ECR source, respectively.

An IED observed at the grounded chamber wall is determined by the bias-induced variation in plasma potential and will be related to the true IED at the biased electrode through the ratio of electrode sheath impedance to wall sheath impedance $\left(Z_{\mathrm{e}} / Z_{\mathrm{w}}\right)$. When the capacitive component of impedance dominates (as is the case in a CCP), then $Z_{\mathrm{w}} \ll Z_{\mathrm{e}}$, due to the much larger wall area, and the wall sheath voltage is a small fraction of the rf-biased voltage. This factor may explain our observed peak energies of $\sim 80 \mathrm{~V}$ which are much less than the dc bias $(450 \mathrm{~V})$. Also, measurements of the RF component of the plasma potential in a similar CCP system [22] show magnitudes around $10 \mathrm{~V}$, similar to the FWHM of the IED peaks. It is reasonable to assume therefore that the true substrate IED in the CCP case is not represented by the IED measured at the wall. Instead, using published data and models $[19,23]$, we would expect a pure bimodal peaked distribution centred at $V_{\text {bias }}$ and with an energy spread of $k V_{\text {bias }}$, where $k \sim$ $0.1-0.3$. However, this applies only for a truly collisionless plasma ( $p<1$ mTorr) and for pressures around 7 mTorr we could expect a flat energy distribution from zero to $V_{\text {bias }}$ with numerous superimposed peaks, due to sheath collisions [23]. As the bias is reduced, the background distribution becomes more asymmetric, with the lower energies dominant. A similar trend is described by Manenschijn et al [19]. These peaks have been attributed to CE collisions while elastic ion-neutral scattering results in a broad, smooth background distribution.

The shape of the measured ICP IEDs, within the bimodal region (i.e. excluding lower energy collisional peaks), can be characterized by a number of related parameters, namely centre energy $\left(E_{\text {mid }}\right)$, mean energy $\left(E_{\text {mean }}\right)$, energy width (FWHM) $(\Delta E)$, high- and low-energy peak positions $\left(E_{\mathrm{H}}, E_{\mathrm{L}}\right)$ and amplitude ratio $(I)$ for ion counts at $E_{\mathrm{H}} / E_{\mathrm{L}}$. From a film growth perspective, we ideally require a small value of $\Delta E$ and a high value of $I$, tuneable over the energy range, as this allows a definitive exploration of IE effect on growth models. $\Delta E$ is determined by the rf-biased amplitude at low frequency but at very high frequencies ions traverse the sheath over multiple RF periods and 'see' only an average sheath potential. A number of analytical expressions have been derived [18] which relate $\Delta E$ to ion mass and frequency, namely

$$
\frac{\Delta E}{V_{\mathrm{pp}}}=\frac{2 e}{\pi}\left(\frac{\tau_{\text {ion }}}{T}\right)^{-1}
$$

and

$$
\frac{\Delta E}{V_{\mathrm{pp}}}=e\left(1+\left(\frac{2.25 \tau_{\mathrm{ion}}}{T}\right)^{2}\right)^{-1}
$$




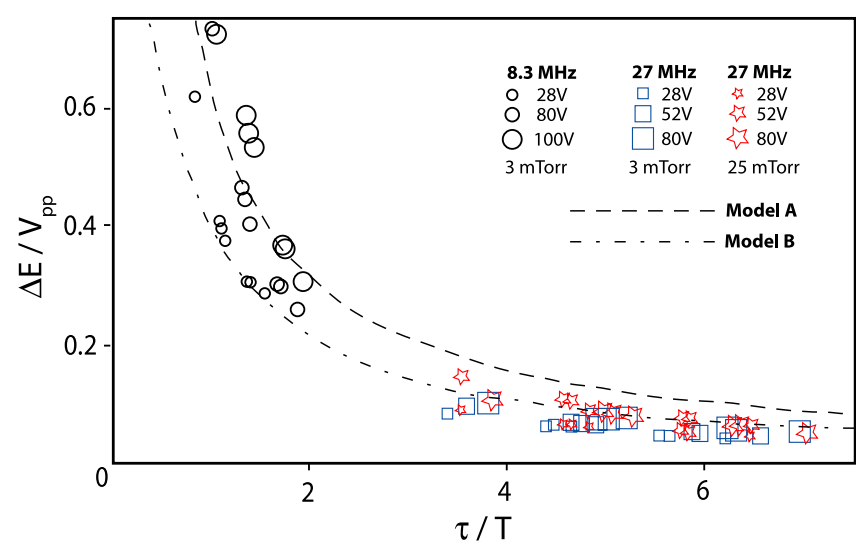

Figure 14. Measured (symbols) and model [18] (dotted curves) values of $\Delta E / V_{\mathrm{pp}}$, the normalized separation between the two peaks in the IEDs, as a function of the ratio of ion transit time $\tau$ to $\mathrm{rf}$ time period $T$ at an ICP input power of $200 \mathrm{~W}$ at pressures of 3.3 and 25 mTorr for varying $V_{\text {bias }}$ and $f_{\text {bias }}$.

where $V_{\mathrm{pp}}$ is the peak-to-peak rf-biased voltage and $\tau / T$ is the ratio of the ion transit time to the rf period, given by

$$
\frac{\tau}{T}=2\left(\frac{V_{\mathrm{pp}}}{2 e m^{*}}\right)^{1 / 4}\left(\frac{m_{\mathrm{ion}} \varepsilon_{0}}{J_{+}}\right)^{1 / 2} f
$$

where $m^{*}$ is the weighted average ion mass, $J_{+}$the total ion flux, $m_{\text {ion }}$ the ion mass and $f$ the frequency. The second model (B), equation (2), accounts for the low frequency situation where ions can follow the slowly changing voltage and $\Delta E / V_{\mathrm{pp}}=1$.

In figure 14, we plot measured $\Delta E / V_{\mathrm{pp}}$ against $\tau / T$ for $8.311 \mathrm{MHz}$ and $27 \mathrm{MHz}$ for $3.3 \mathrm{mTorr}$ and 25 mTorr, and compare with model A, equation (1) and model B, equation (2). We used an estimate of the total flux from flux probe and Langmuir probe measurements and $V_{\mathrm{pp}}$ was obtained from voltage measurement near the electrode, adjusted to account for transmission line effects, to which was added the value of plasma potential $(\sim 20 \mathrm{~V})$. Since the waveform contains significant harmonic content, the electrical distance between the measure point and the electrode needs to be considered as a transmission line, in order to obtain the true voltage. We have derived an equivalent electrical model for this system and estimate that the actual electrode voltage can be up to $30 \%$ higher. At high frequencies, $\Delta E / V_{\mathrm{pp}}$ is very small $(\sim 0.1)$ and follows closely model $\mathrm{B}$, whereas at $8.311 \mathrm{MHz}$, the energy width is much greater and the data lie closer to model A, which does not account for the low frequency situation. However, errors in determining sheath potential difference must be considered here as the measured bias waveforms sometimes show a high harmonic content. Also the plasma impedance and the rf component of the plasma potential also need to be considered and these can vary considerably with plasma conditions [24].

The ICP bimodal IED structures are well developed, even at relatively high pressures of 25 mTorr, where for CCP conditions collisional effects have been reported to be dominant [23]. The likely reason for this is the much smaller sheath width in an ICP. In our case, average sheath widths are estimated, optically, to be around $0.5 \mathrm{~mm}$ compared with reported CCP values of 5-10 mm. In our ICP IEDs, figures $3-5$, the presence of low $\left(E<e V_{\text {bias }}\right)$ energy ions which appear as peaks and broader distributions is due to elastic and CE collisions within the sheath, the latter cross-section is normally the larger. These are visible for $\mathrm{Ar}^{+}$, the dominant ion species, only. Very low or almost zero collisional counts are observed for $\mathrm{ArH}^{+}$, which has similar count rates to $\mathrm{Ar}^{+}$ overall, and at high pressure, figure 5, is the dominant ion. This strongly suggests resonant CE between ion and its parent neutral dominates. Under the IE measurement conditions, the dominant neutral is argon, with $\mathrm{C}_{2} \mathrm{H}_{2}$ almost zero [4]. Ikkurthi et al [60] have observed a similar absence of collisional counts for $\mathrm{ArH}^{+}$in $\mathrm{Ar}-\mathrm{CH}_{4}$ plasmas, while Georgieva et al [57] report similar results for $\mathrm{Ar}-\mathrm{CF}_{4}-\mathrm{N}_{2}$ mixtures where $\mathrm{Ar}^{+}$and $\mathrm{N}^{+}$IED showed well-developed collisional peaks, these were absent for the main radical ions, $\mathrm{CF}_{3}^{+}$, since the radical neutral density is so low.

With CE collisions, a fast ion transfers its charge to slow thermal neutrals resulting in fast neutrals and slow ions. This leads to a broadening of the IED, a shift to lower energies and the appearance of secondary peaks at lower energies than the main collisionless peak(s) [23]. Such collisions will occur throughout the region of the maximum sheath excursion and when a slow ion is created in the electric field region, it is accelerated and ultimately arrives at the cathode with a lower energy compared with a collision free ion, since it did not experience the full potential drop. However, ions created at a position behind the retreating sheath are essentially at rest, since the electric field is $\sim 0$, and remain so until the sheath returns to this position, whereupon all such ions are accelerated together, ultimately arriving at the cathode with the same energy. The value of this energy varies with the position at which the ions were created and the energyposition curve shows a number of turning points $(\mathrm{d} E / \mathrm{d} x=0)$ which correspond with the secondary peaks in the IED and these appear therefore only for the high-frequency case where $\tau / T>1$. Wild and Koidl [23] present a detailed model to explain the appearance and position of collision peaks and show that the number of peaks is $\sim \tau / T$, i.e. for an ion traversing the sheath region in $N$ rf-periods, the sheath edge will cross the ion path $\sim N$ times and result in $\sim N$ ion bunches. They define a plasma scaling factor $\eta\left(=e V_{\mathrm{pp}} / m_{\text {ion }} \omega^{2} d^{2}\right)$ as a model parameter and give an approximate relationship for $\tau / T$ as $1 / \pi \sqrt{(2 \eta)}$.

In table 1, a summary of observed $\mathrm{Ar}^{+}$collisional peaks characteristics is given for various frequencies and pressures. For the lower frequency $(8.3 \mathrm{MHz})$ a single broad peak is observed, with FWHM increasing with bias. This peak accounts for $23 \%$ on average of total ion flux, depending on bias, and nearly all the collisional flux. At higher frequency $(27 \mathrm{MHz})$ and pressure $(25 \mathrm{mTorr})$, this peak is slightly narrower and accounts for an average of $32 \%$ of total ion flux and $72 \%$ of collisional flux, since under these conditions, a second smaller collisional peak is observed in most cases. Sheath widths at $8.3 \mathrm{MHz}(100 \mathrm{~V}$ bias $)$, estimated from semi-analytical models [61, 62], range from 0.6 to $1.2 \mathrm{~mm}$ for a measured electron density of $4 \times 10^{10} \mathrm{~cm}^{-3}$ and electron temperature of $3 \mathrm{eV}$ and is the same order as our estimated 
Table 1. Summary data for low-energy $\mathrm{Ar}^{+}$collisional counts for variable frequency and pressure.

\begin{tabular}{|c|c|c|c|c|c|c|c|c|c|c|c|c|}
\hline \multirow[b]{2}{*}{$\begin{array}{l}f \\
(\mathrm{MHz})\end{array}$} & \multirow[b]{2}{*}{$\begin{array}{l}p \\
\text { (m Torr) }\end{array}$} & \multirow[b]{2}{*}{$\begin{array}{l}\text { Bias } \\
\text { (V) }\end{array}$} & \multicolumn{5}{|c|}{ First collisional peak } & \multicolumn{5}{|c|}{ Second collisional peak } \\
\hline & & & $\begin{array}{l}\text { Energy } \\
(\mathrm{eV})\end{array}$ & $I^{\mathrm{a}}$ & $\begin{array}{l}\text { FWHM } \\
(\mathrm{eV})\end{array}$ & Count $^{\mathrm{b}}$ & $\%$ Coll. $^{\mathrm{c}}$ & $\begin{array}{l}\text { Energy } \\
(\mathrm{eV})\end{array}$ & $I^{\mathrm{a}}$ & $\begin{array}{l}\text { FWHM } \\
(\mathrm{eV})\end{array}$ & $\%$ Count $^{\mathrm{b}}$ & $\%$ Coll $^{\mathrm{c}}$ \\
\hline \multirow[t]{3}{*}{8.3} & 3.3 & 28 & 4 & 0.22 & 7 & $14 \%$ & $62 \%$ & & & & & \\
\hline & & 82 & 16 & 0.71 & 12 & $29 \%$ & $92 \%$ & & & & & \\
\hline & & 100 & 24 & 0.39 & 23 & $25 \%$ & $87 \%$ & & & & & \\
\hline \multirow[t]{3}{*}{27} & 3.3 & 28 & 10 & 0.24 & 11 & $18 \%$ & $73 \%$ & 23.5 & 0.08 & 8 & $6 \%$ & $25 \%$ \\
\hline & & 52 & 11.5 & 0.89 & 6.5 & $34 \%$ & $72 \%$ & 30 & 0.15 & 33 & $10 \%$ & $20 \%$ \\
\hline & & 80 & 21 & 0.55 & 9 & $29 \%$ & $60 \%$ & 45.5 & 0.19 & 11 & $14 \%$ & $30 \%$ \\
\hline \multirow[t]{3}{*}{27} & 25 & 28 & 0 & 1.25 & 14 & $35 \%$ & $72 \%$ & & & & & \\
\hline & & 52 & 11 & 0.60 & 14 & $36 \%$ & $77 \%$ & 32 & 0.34 & 12 & $21 \%$ & $46 \%$ \\
\hline & & 80 & 22 & 1.00 & 8 & $37 \%$ & $78 \%$ & 30 & 0.65 & 20 & $29 \%$ & $62 \%$ \\
\hline
\end{tabular}

a Peak height as a fraction of highest collisionless peak.

${ }^{\mathrm{b}}$ Collisional peak counts as a percentage of total counts across full energy range.

${ }^{\mathrm{c}}$ Collisional peak counts as a percentage of total collisional counts in the low-energy range.

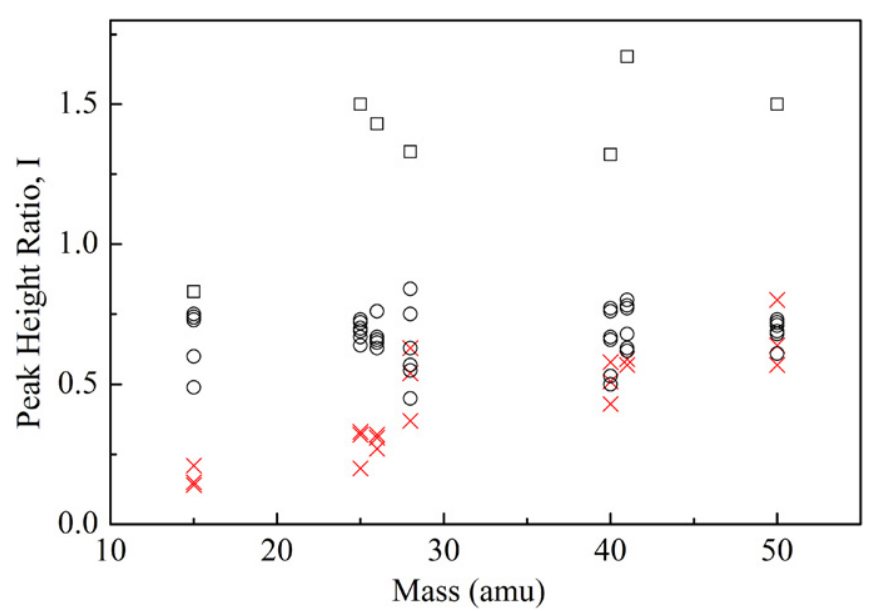

Figure 15. IED peak height ratio against mass for the seven dominant species. Squares: $V_{\text {bias }}=7 \mathrm{~V} f_{\text {bias }}=8.311 \mathrm{MHz}$. Crosses: $V_{\text {bias }}>28 \mathrm{~V} f_{\text {bias }}=8.311 \mathrm{MHz}$. Circles: $V_{\text {bias }}>28 \mathrm{~V}$ $f_{\text {bias }}=27 \mathrm{MHz}$.

values from optical measurements, $\sim 0.5 \mathrm{~mm}$. Wild and Koidl [23] predict $\tau / T \sim 1$ and single or limited CE peaks, for sheath thicknesses in the range $0.5-0.9 \mathrm{~mm}$ and biases up to $100 \mathrm{~V}$ [63]. For an energy range $0-100 \mathrm{eV}$, the mean free path for $\mathrm{Ar}^{+}$ collisions at $3.3 \mathrm{mTorr}$ is in the range $6-10 \mathrm{~mm}$ and at $25 \mathrm{mTorr}$ is $\leqslant 1 \mathrm{~mm}$. In summary, the observed rf modulation of the ionbombardment energy is expected for plasmas operated in the low to intermediate frequency range where the ion transit time is approximately the rf period. However, for sheath widths less than or equal to the mean free path, collisions are limited, and account for a maximum of $30 \%$ of ion flux.

One, rarely considered, aspect of the bimodal structure is the ratio of the high and low peak heights $(I)$ which impact on the average IE. Highly asymmetric distributions can be considered equivalent to monoenergetic beams, ideal for film growth modelling. For all conditions, except for the lowest bias $(7 \mathrm{~V})$ at $8.311 \mathrm{MHz}$, the ratio $I$ is less than 1 . At $27 \mathrm{MHz}$, it is approximately constant $(0.5-0.75)$ across bias and pressure while for $8.311 \mathrm{MHz}$ it tends to increase with bias, figure 15 .

To date, little attention has been paid to this characteristic in the literature. We have constructed a simple numerical

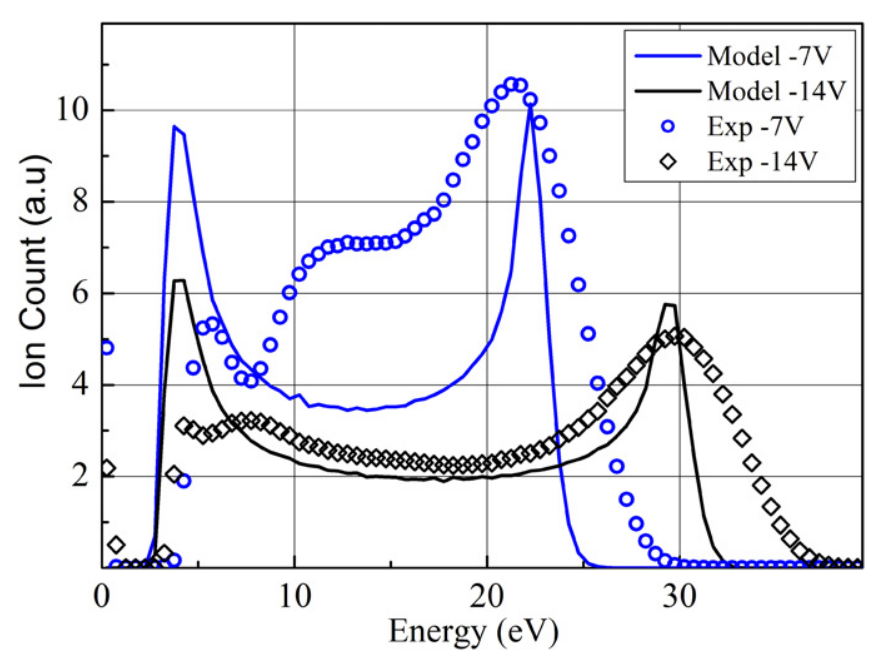

Figure 16. One-dimensional ion track model IED (line) obtained for two $V_{\text {bias }}$ at $f_{\text {bias }}=8.311 \mathrm{MHz}$ using pure sinusoidal bias waveform compared with the measured IED (marker): 3.3 mTorr $\mathrm{C}_{2} \mathrm{H}_{2}$ : Ar (flow ratio $2: 1$ ) and same substrate bias condition.

ion track model to investigate the factors influencing the ratio I using an RF sheath model [25] based on a single-species Child-Langmuir sheath under rf excitation. The model inputs are the measured electron temperature $\left(T_{\mathrm{e}}\right)$ and density $\left(n_{\mathrm{e}}\right)$ from [4] and $V_{\text {pe }}$, the time-varying potential across the sheath determined from rf voltage measurements close to the electrode and the plasma potential $V_{\mathrm{pl}}$. The rf period is divided into 1200 time steps and single ions are injected into the sheath at each time step, with a velocity derived from the Bohm criterion [25]. The sheath potential variation is divided into 500 equal distance steps and an estimate of average sheath width is obtained from optical measurements and then adjusted to obtain the best fit for the low-energy cut-off point in the bimodal part of the IED. The applied voltage is assumed sinusoidal and the small rf ripple on $V_{\mathrm{pl}}$ is ignored.

Figure 16 shows a good fit between the model and measured data at low biases of $7 \mathrm{~V}$ and $14 \mathrm{~V}$, although the measurement exhibits a double peak in the low-energy region. At higher biases the model fit is much less reliable. This is partly due to discretization errors, given the model simplicity. 


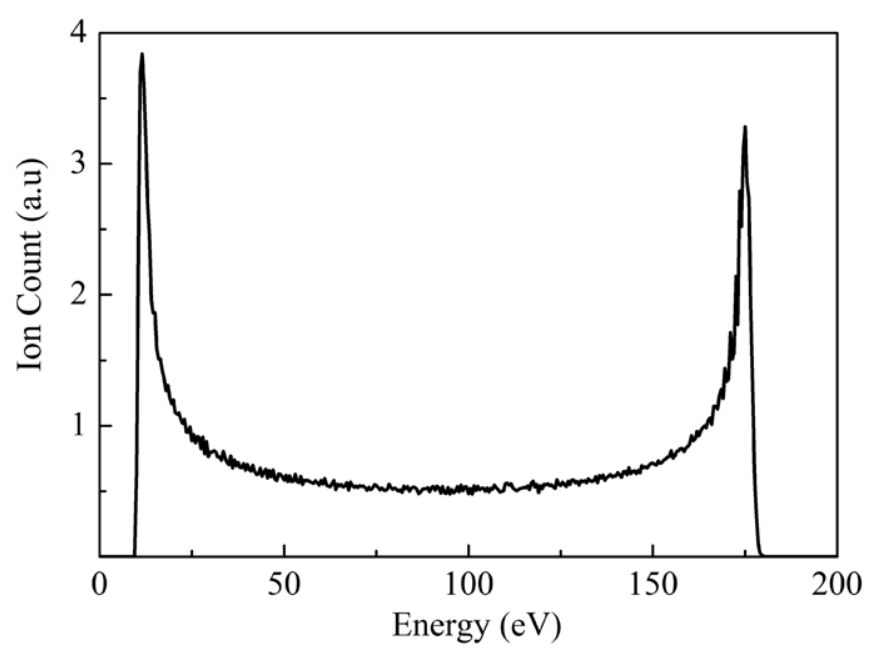

Figure 17. Modelled IED, $V_{\text {bias }}=85 \mathrm{~V}$ pure sinusoid. 1200 ions, Gaussian velocity distribution assumed. Peak ratio $\sim 1$ (almost symmetric).
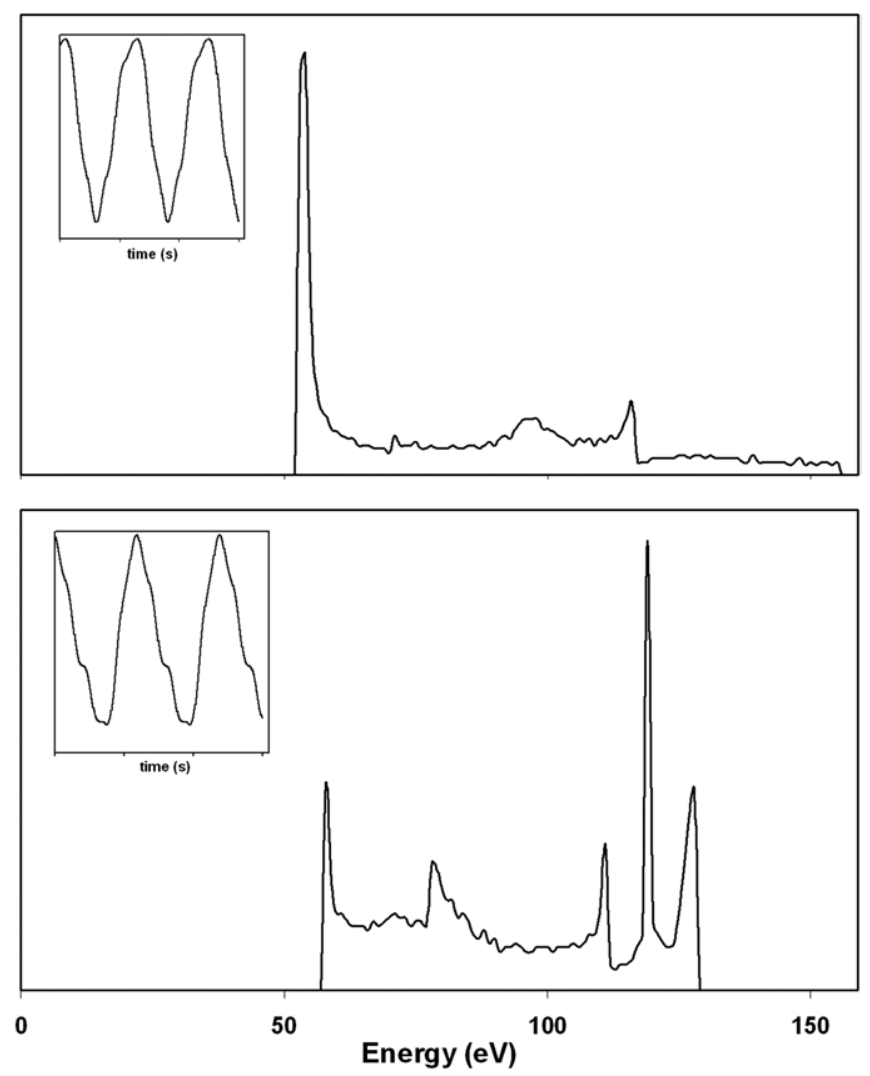

Figure 18. One-dimensional ion track modelled IEDs for two different harmonically rich waveforms.

However, much more critical is the shape of the input bias waveform. In figure 17 , the model output is given for a pure sinusoidal input at $85 \mathrm{~V}$ bias $(8.311 \mathrm{MHz})$ and the peak ratio is $\sim 1$ as observed with the measured data. In figure 18 , two different harmonically rich waveforms are input and the resulting IEDs peak ratios show extreme values of $I \gg 1$ or $I \sim 0$.

While ICP processing offers the opportunity for greater control of IE range compared with $\mathrm{CCP}$, realizing a highly monoenergetic ion beam would be valuable for control of film growth. One approach, suggested by these results, is to use high-frequency biasing. Alternatively, the observed sensitivity to waveform harmonic content offers the possibility of IED tailoring using multi-frequency biasing.

\subsection{Film deposition}

A small number of films were deposited at a single bias frequency $(8.311 \mathrm{MHz})$ in order to confirm that the conditions for plasma species measurements were suitable for film growth. No attempt was made at this stage to optimize growth conditions for adhesion, thickness, hardness, etc. The major difference between films deposited by ICP and CCP is the peaked response in the hardness-bias curve for the ICP case. At low biases the softer films are consistent with a relatively high hydrogen content, as evidenced by the Raman baseline slope, figure 11, and the higher growth rate, figure 8, which implies a reduced density since the arriving species flux varies little across the bias range. Similar quality films are often obtained at the grounded electrode of a CCP. On the high bias side, the soft films exhibit low hydrogen content and are more graphite-like, as found with CCP films deposited under very high bias. It is expected that high-energy ion bombardment will cause hydrogen depletion and allow the remaining $\mathrm{C}$ atoms to re-arrange via $\mathrm{sp}^{2}$-bonding. The striking feature here, however, is the relatively low value of energy required and the appearance of a very sharp threshold between 90 and $100 \mathrm{eV}$.

The growth of amorphous carbon films and their bonding structure is known to be a very complicated function of ion, neutral and radical interactions with a dynamic surface (and sub-surface) and these interactions lead to competing effects such as deposition and etching or diamond versus graphite bonding. Much of this complexity arises from the presence of hydrogen and hydrogenated species. In this paper we have sought to provide the necessary data regarding impinging ion flux and associated ion energies to allow greater insight into the 'ionic' component of this growth process. We have included brief results of grown film properties which can act as a calibration of our systems linking plasma conditions and materials while also offering insight into potential growth mechanisms that are worth further investigation. The main distinguishing features of ICP deposition is the strongly peaked response of the film properties to substrate bias and the dominance of argon in the ion-bombardment species, compared with $\mathrm{C}_{2} \mathrm{H}_{2}^{+}$for the $\mathrm{CCP}$ case. To elucidate potential ionic mechanisms, we consider elements of two (hydrogen-free) growth processes where ion bombardment has been investigated, namely (i) the high $\mathrm{sp}^{3}$ tetrahedral (ta-C) case formed by carbon ion bombardment and (ii) the low $\mathrm{sp}^{3}$-case (sputtered) where additional inert ion bombardment increases $\mathrm{sp}^{3}$-bonding. In both cases the concept of optimal energy is considered whereby lowenergy bombardment is insufficient for $\mathrm{sp}^{3}$-bond formation while high-energy bombardment leads to thermally induced relaxation of $\mathrm{sp}^{3}$-bonds to $\mathrm{sp}^{2}$-configuration. This is followed by (iii) a discussion regarding the width of the IED, the effect of a range of ion energies on these competing bond-formation 
processes and the difference between ICP and CCP conditions in this respect.

The shape of ICP hardness characteristic is similar to that obtained for our hydrogen-free tetrahedral amorphous carbon (ta-C), figure 13. However, ta-C is formed by (mainly) $\mathrm{C}^{+}$ion bombardment and the high $\mathrm{sp}^{3}$-fraction and hardness values arise from sub-surface carbon implantation in a restricted volume. Surface penetration and atom displacement energy thresholds must be overcome to achieve $\mathrm{sp}^{3}$-bonding otherwise low-energy ions are simply adsorbed on the surface in $\mathrm{sp}^{2}$-configuration. However, excess IE causes thermal relaxation of the $\mathrm{sp}^{3}$-bonds to the natural $\mathrm{sp}^{2}$-state. In the ICP case, however, we can consider the ion flux to consist of only $\mathrm{Ar}^{+}$ions and hence the ta-C model is only appropriate for carbon species implantation via $\mathrm{Ar}^{+}$induced knock-on of surface adsorbed carbon species. The ICP hardness characteristic also shares some similarity with that of hydrogen-free sputtered films $[12,13]$, figure 13 . Normally, sputtered films are relatively soft and graphite-like $\left(\mathrm{sp}^{2}>\right.$ $80 \%$ ) since the carbon flux has low energy. With an unbalanced magnetron configuration and added substrate bias, the substrate ion flux and energy are enhanced such that the adsorbed carbon atoms are bombarded by $\mathrm{Ar}^{+}$ions, allowing knock-on implantation to increase the $\mathrm{sp}^{3}$-bonding. The resultant hardness maximum occurs around $50 \mathrm{~V}$ (negative) bias and falls off slowly thereafter. Therefore, our results show that the concept of an optimal ion-bombardment energy for high $\mathrm{sp}^{3}$-bond formation may apply to a-C : $\mathrm{H}$ films as it does to ta-C films. However, confirmation of this requires growth in almost monoenergetic ion-bombardment conditions. Under normal plasma conditions, this is difficult to achieve and hence the range of actual energies will overlap the optimal and nonoptimal film growth conditions. Calculations for ta-C [26] show a maximum implantation effect at $90 \mathrm{eV}$ per $\mathrm{C}$ atom and an effective penetration threshold of $\sim 44 \mathrm{eV}$. However, the thermal relaxation process occurs over a $>50 \mathrm{eV}$ 'range' above the peak energy, much larger than that observed here for ICP $(<10 \mathrm{eV})$. A similar range was obtained from an implantation model for sputtered films [27] with a peak at energies around $80 \mathrm{eV}$. However, the model used arbitrary fitting parameters to match the width of the characteristic to experimental sputtered values. Reconciliation of this relaxation factor with the ICP results may be possible by considering additional effects due to higher energy ions $(>130 \mathrm{eV})$ present under the $100 \mathrm{~V}$ bias conditions, given the greater $\Delta E$. To account for the IE spread, the hardness data from figure 10 are replotted, in figure 19, against mean IE $(E)$ and energy spread $(\Delta E)$. Also included are the nominal values of applied substrate bias. In the ICP, the flux of such high-energy ions is low and the IED width versus hardness characteristic may therefore suggest a relatively simple relationship between ion flux and bondtype formation. This, however, is difficult to reconcile with the conditions in the $\mathrm{CCP}$ where high $\mathrm{sp}^{3}$-fraction films are obtained across a much wider bias window (150-500 V). We have not been able to measure the IEDs directly at the powered electrode in our CCP system. From our measurements at the wall and by comparison with the simulations of Georgieva et al [57] for $\mathrm{Ar}^{+}, \mathrm{CF}_{3}^{+}$and $\mathrm{N}_{2}^{+}$, as well as the measurements

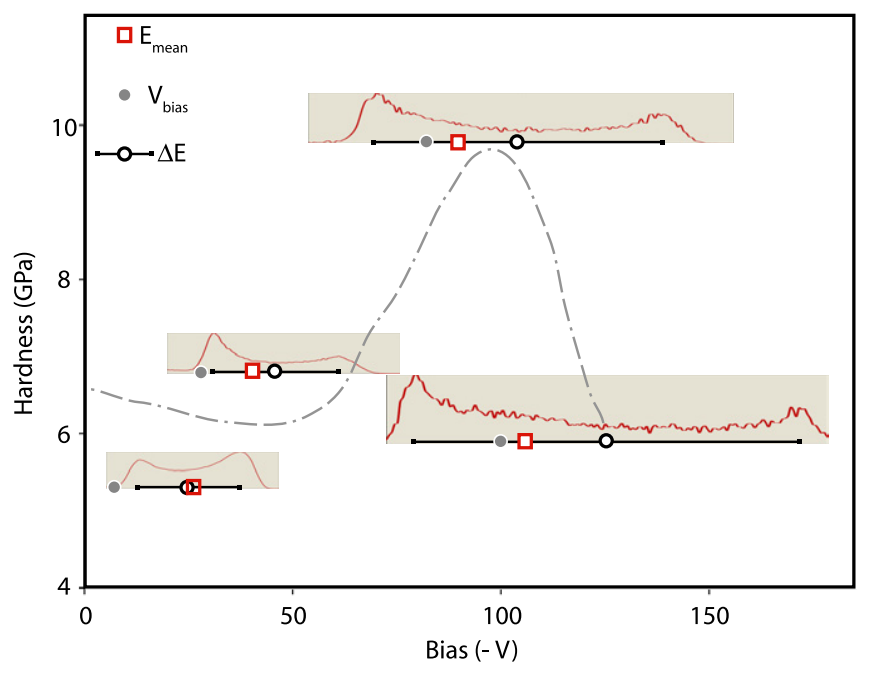

Figure 19. The hardness versus substrate bias curve from figure 10 is replotted to indicate hardness variation with respect to average ion-bombardment energy $E_{\text {mean }}$ (red squares) and the energy range, $\Delta E$. Data were calculated from the bimodal portions of the respective IEDs, ignoring collisional peaks, shown inset for each bias. The original $V_{\text {bias }}$ trend, from figure 10, is illustrated via the dotted line.

and simulations of Sobolewski et al [18] for $\mathrm{C}_{x} \mathrm{~F}_{y}^{+}$ions (from $\mathrm{CF}_{4}$ ), we can expect the powered IED in our case to be similar in shape to that observed at the wall except shifted to a higher energy, commensurate with the dc bias and much higher than the ICP case, and for the $\mathrm{C}_{2} \mathrm{H}_{2}^{+}$ion to be dominant. The presence of lower energy ions due to collisions may be more prominent than that observed at the wall, figure 2, given the larger sheath width. This difference in growth dependence on IE between CCP and ICP systems is significant, implying different mechanisms according to whether inert (ICP) or carbon-carrying (CCP) ions are involved. The dominance of the $\mathrm{C}_{2} \mathrm{H}_{2}^{+}$ion in the $\mathrm{CCP}$ case should lead to direct carbon implantation whereas with $\mathrm{Ar}^{+}$bombardment, an indirect ionstitching [2] mechanism is likely. Other ion-bombardment effects, i.e. surface hydrogen removal, creation of surface dangling bonds, sub-surface reorganization and $\mathrm{H}$ removal, must also be involved in film formation and these alternative reaction channels may be promoted in the absence of direct bond formation during $\mathrm{Ar}^{+}$bombardment. Finally, although beyond the scope of this paper, it should be noted that high hardness amorphous carbon films have been obtained [28] without significant ion flux or energy using an expanding thermal plasma to dissociate acetylene and create a high flux of $\mathrm{C}_{2} \mathrm{H}$ radicals. This radical dominated reaction channel may be of some importance in ICP film formation due to the almost total $\mathrm{C}_{2} \mathrm{H}_{2}$ dissociation and high $\mathrm{C}_{2} \mathrm{H}$ radical production rate [4].

Finally, the effect of pressure on film deposition was briefly investigated. For a set pressure of 60 mTorr, the working plasma pressure was 20 mTorr and the IED exhibited a single peak for $\mathrm{Ar}^{+}$at the bias voltage (or plasma potential for the unbiased case), figure 7. No lower energy collisional peaks were observed. The film hardness was found to be reduced by more than a factor of 2 compared with the low pressure case although the IE was at the optimum value 
$\sim 90 \mathrm{eV}$. For higher pressures (120 mTorr working pressure) a low-energy collisional peak is dominant and the hardness is further reduced. At these high pressures, the ion fluxes are significantly less than at low pressure. Nevertheless, the effect of ion bombardment is still observable in the difference in hardness for biased and unbiased films, figure 12 .

\section{Conclusion}

Ion energy distributions have been determined at the rf-driven electrode in an inductively coupled acetylene-argon plasma for various substrate bias voltages and frequencies under conditions suitable for film deposition. The plasma ion content is predominantly $\mathrm{Ar}^{+}$or $\mathrm{ArH}^{+}$despite the set flow ratio of $\mathrm{C}_{2} \mathrm{H}_{2}$ : Ar of 2:1 due to the high dissociation of the parent molecule [4]. For a range of pressures, up to 25 mTorr, the IEDs exhibit well-developed bimodal structures with peak separation values that follow the expected dependence on voltage and frequency. Additional lower energy collisional peaks are also observed. At higher pressures, up to 120 mTorr, the bimodal structure is replaced by a single peak and the low-energy collisional peaks become dominant. Low pressure deposited diamond-like carbon films indicate a peak hardness at an ion energy of around $90 \mathrm{eV}$ and a very sharp fall in hardness beyond this. This is similar to models of $\mathrm{sp}^{3}$-bond formation in hydrogen-free tetrahedral amorphous carbon or bias-sputtered films. However, due to the lack of carbon-based ions, the mechanism may be attributed to argon knock-on implantation of surface adsorbed carbon species. Other, complementary ion- and radical-based growth mechanisms are also likely to be involved. While the direct comparison of ion energy distributions and film characteristics has provided useful insight into growth mechanisms, greater control of the IED width would be beneficial in providing almost monoenergetic ion beams under true plasma deposition conditions. Results from this work have shown that use of highfrequency bias or bias harmonics may lead to much narrower distributions and film deposition under these conditions is currently under investigation.

\section{References}

[1] Jacob W 1998 Thin Solid Films 326 1-42

[2] von Keudell A, Meier M and Hopf C 2002 Diamond Relat. Mater. 11 969-75

[3] Gielen J W A M, van de Sanden M C M and Schram D C 1995 Thin Solid Films 271 56-63

[4] Baby A, Mahony C M O and Maguire P D 2011 Plasma Sources Sci. Technol. 20015003

[5] Lemoine $\mathrm{P}$ et al 2000 Wear 244 79-84

[6] Lemoine P, Quinn J P, Maguire P D and McLaughlin J A 2004 Wear 257 509-22

[7] Ogwu A A, Lamberton R W, Morley S, Maguire P D and McLaughlin J A 1999 Physica B 269 335-44

[8] Ogwu A A, Lamberton R W, Maguire P D and McLaughlin J A 1999 J. Phys. D: Appl. Phys. 32 981-7

[9] Maguire P D et al 2005 Diamond Relat. Mater. 14 1277-88

[10] Abbas G A, McLaughlin J A and Harkin-Jones E 2004 Diamond Relat. Mater. 13 1342-5

[11] Quinn J P, Lemoine P, Maguire P and McLaughlin J A 2004 Diamond Relat. Mater. 13 1385-90
[12] Ahmad I, Roy S S, Maguire P D, Papakonstantinou P and McLaughlin J A 2005 Thin Solid Films 482 45-9

[13] Ahmad I, Maguire P D, Lemoine P, Roy S S and McLaughlin J A 2004 Diamond Relat. Mater. 13 1346-9

[14] De Graaf A, Van Hest M F A M, Van De Sanden M C M, Letourneur K G Y and Schram D C 1999 Appl. Phys. Lett. 74 2927-9

[15] Zhou J, Martin I T, Ayers R, Adams E, Liu D and Fisher E R 2006 Plasma Sources Sci. Technol. 15 714-26

[16] Bauer M, Schwarz-Selinger T, Jacob W and von Keudell A 2005 J. Appl. Phys. 98 73302-1

[17] Economou D J 2000 Thin Solid Films 365 348-67

[18] Sobolewski M A, Yicheng Wang and Goyette A $2002 \mathrm{~J}$. Appl. Phys. 91 6303-14

[19] Manenschijn A, Janssen G C A M, van der Drift E and Radelaar S 1991 J. Appl. Phys. 69 1253-62

[20] Coburn J W and Kay E 1972 J. Appl. Phys. 43 4965-71

[21] Tatsuta T, Tachibana K and Tsuji O 1994 Japan. J. Appl. Phys. Part 133 6341-9

[22] Graham W G, Mahony C M O and Steen P G 2000 Vacuum $563-8$

[23] Wild C and Koidl P 1991 J. Appl. Phys. 69 2909-22

[24] Schauer J, Hong S and Winter J 2004 Plasma Sources Sci. Technol. 13 636-45

[25] Lieberman M A and Lichtenberg A J 1994 Principles of Plasma Discharge and Materials Processing (New York: Wiley-Interscience)

[26] Robertson J 2002 Mater. Sci. Eng. R: Rep. 37 1-281

[27] Logothetidis S, Patsalas P, Gioti M, Galdikas A and Pranevicius L 2000 Thin Solid Films 376 56-66

[28] Gielen J W A M, Kessels W M M, van de Sanden M C M and Schram D C 1997 J. Appl. Phys. 82 2643-54

[29] Tsui R T C 1967 Phys. Rev. 168 107-13

[30] Benoit-Cattin P and Bernard L C 1969 J. Appl. Phys. 39 5723-6

[31] Kohler K, Horne D E and Coburn J W 1985 J. Appl. Phys. 583350

[32] Kuypers A D and Hopman H J 1988 J. Appl. Phys. 631894

[33] Kawamura E, Vahedi V, Lieberman M A and Birdsall C K 1998 Plasma Sources Sci. Technol. 8 R45

[34] Miller P A and Riley M E 1997 J. Appl. Phys. 823689

[35] Kortshagen U and Zethoff N I 1995 Plasma Sources Sci. Technol. 4541

[36] Woodworth J R, Abraham I C, Riley M E, Miller P A, Hamilton T W and Aragon B P 2002 J. Vac. Sci. Technol. A 20873

[37] Hopwood J 1993 Appl. Phys. Lett. 62940

[38] Reinke P, Schelz S, Jacob W and Moller W 1992 J. Vac. Sci. Technol. A 10 434-8

[39] Amemiya H, Ishii S and Shigueoka Y 1991 Japan. J. Appl. Phys. Part 130 376-84

[40] Pecher P and Jacob W 1998 Appl. Phys. Lett. 7331

[41] Janes J and Huth C 1992 J. Vac. Sci. Technol. A 103086

[42] Edelberg E A, Perry A, Benjamin N and Aydil E S 1999 J. Vac. Sci. Technol. A 17506

[43] Edelberg E A and Aydil E S 1999 J. Appl. Phys. 864799

[44] Gahan D, Dolinaj B and Hopkins M B 2008 Rev. Sci. Intrum. 79033502

[45] Wang Y and Olthoff J K 1999 J. Appl. Phys. 856358

[46] Rusu I A, Popa G and Sullivan J L 2002 J. Phys. D: Appl. Phys. 352808

[47] O'Connell D, Zorat R, Ellingboe A R and Turner M M 2007 Phys. Plasmas 14103510

[48] Mizutani N, Nagata Y, Kubo A and Hayashi T 1998 Rev. Sci. Instrum. 691918

[49] Mizutani N and Hayashi T 2000 Thin Solid Films 374167

[50] Hallil A, Zabeida O, Wertheimer M R and Martinua L 2000 J. Vac. Sci. Technol. A 18882 
[51] Abraham I C, Woodworth J R, Riley M E, Miller P A, Hamilton T W and Aragon B P 2002 J. Vac. Sci. Technol. A 201759

[52] Metze A, Ernie D W and Oskam H J 1989 J. Appl. Phys. 65993

[53] Kushner M J 1985 J. Appl. Phys. 584024

[54] Vender D and Boswell R W 1990 IEEE Trans. Plasma Sci. 18725

[55] Dai Z L, Wang Y N and Ma T C 2002 Phys. Rev. E 65036403

[56] Dai Z L and Wang Y N 2004 Phys. Rev. E 69036403

[57] Georgieva V, Bogaerts A and Gijbels R 2004 Phys. Rev. E 69026406
[58] Olevanov M, Proshina O, Rakhimova T and Voloshin D 2008 Phys. Rev. E 78026404

[59] Lee S H, Tiwari P K and Lee J K 2009 Plasma Sources Sci. Technol. 18025024

[60] Ikkurthi V R, Matyash K, Meichsner J, Melzer A and Schneider R 2009 Plasma Sources Sci. Technol. 18035003

[61] Lieberman M A 1988 IEEE Trans. Plasma Sci. 16638

[62] Panagopoulos T and Economou D J 1999 J. Appl. Phys. 853435

[63] McDaniel E W, Mitchell J B A and Rudd M E 1993 Atomic Collisions: Heavy Particle Projectiles (New York: Wiley) 